\title{
Electrophysiological evidence for impaired attentional engagement with phonologically acceptable misspellings in developmental dyslexia
}

\author{
Nicola J. Savill ${ }^{*}$ and Guillaume Thierry ${ }^{1,2}$ \\ School of Psychology, Bangor University, Bangor, UK \\ 2 Economic and Social Research Council Centre for Research on Bilingualism in Theory and Practice, Bangor University, Bangor, UK
}

\section{Edited by:}

Marcela G. Pena, University of Chile,

Chile

\section{Reviewed by:}

Robert J. Hartsuiker, University of Ghent, Belgium

Li H. Tan, University of Hong Kong,

China

\section{*Correspondence}

Nicola J. Savill, School of Psychology, Bangor University, Bangor, Gwynedd LL57 2AS, UK.

e-mail:n.j.savill@bangor.ac.uk
Event-related potential (ERP) studies of word recognition have provided fundamental insights into the time-course and stages of visual and auditory word form processing in reading. Here, we used ERPs to track the time-course of phonological processing in dyslexic adults and matched controls. Participants engaged in semantic judgments of visually presented highcloze probability sentences ending either with (a) their best completion word, (b) a homophone of the best completion, (c) a pseudohomophone of the best completion, or (d) an unrelated word, to examine the interplay of phonological and orthographic processing in reading and the stage(s) of processing affected in developmental dyslexia. Early ERP peaks (N1, P2, N2) were modulated in amplitude similarly in the two groups of participants. However, dyslexic readers failed to show the P3a modulation seen in control participants for unexpected homophones and pseudohomophones (i.e., sentence completions that are acceptable phonologically but are misspelt). Furthermore, P3a amplitudes significantly correlated with reaction times in each experimental condition. Our results showed no sign of a deficit in accessing phonological representations during reading, since sentence primes yielded phonological priming effects that did not differ between participant groups in the early phases of processing. On the other hand, we report new evidence for a deficient attentional engagement with orthographically unexpected but phonologically expected words in dyslexia, irrespective of task focus on orthography or phonology. In our view, this result is consistent with deficiency in reading occurring from the point at which attention is oriented to phonological analysis, which may underlie broader difficulties in sublexical decoding.

Keywords: developmental dyslexia, event-related potential, $\mathrm{P} 3$ a, attention, orthographic processing, homophone, reading

\section{INTRODUCTION}

During the last decade, the reading difficulties experienced by individuals with developmental dyslexia have been consistently associated with a deficit in phonological processing (e.g., Snowling, 2000; Ramus, 2002). More specifically, weak phonological coding capacity would be responsible for weak phonological representations of words and, in turn, for difficulties in the learning of graphemephoneme correspondences necessary to decode unfamiliar words, for a deficit in constraining phonological analysis and segmentation, and, finally, for poor performance in phonological awareness tasks (Fowler, 1991; Manis et al., 1997; Swan and Goswami, 1997; Snowling, 2000; Vellutino et al., 2004).

However, evidence for weak phonological representations in developmental dyslexia is limited (see Ramus, 2002; Blomert et al., 2004; Ramus and Szenkovits, 2008) and largely derived from auditory tasks testing sensitivity to speech or acoustically modified stimuli within the context of tasks taxing working memory resources, and which usually require discrimination from a referent (see Ahissar et al., 2006; Banai and Ahissar, 2006, for a discussion). This has prompted alternative proposals of mechanisms that contribute to phonological processing impairments involving working memory during phonological access (Blomert et al., 2004; Ramus and Szenkovits, 2008; Menghini et al., 2011), attentional engagement with phonological information (Hari et al., 1999; Hari and Renvall, 2001; Facoetti et al., 2006, 2008, 2010; Ruffino et al., 2010), visuo-attentional processes engaged in orthographic analysis (e.g., Ans et al., 1998; Valdois et al., 2004; Bosse et al., 2007; Vidyasagar and Pammer, 2010) or perceptual filtering (Roach and Hogben, 2007, 2008; Geiger et al., 2008), or a combination of such more generic cognitive processes (e.g., Pennington and Bishop, 2009; Menghini et al., 2010, 2011).

Behavioral studies are limited in the extent to which they can provide information in support of or against the hypotheses presented above, not only with respect to the magnitude of the impairment but also with regard to the exact point in time when word recognition is affected. Event-related potentials (ERPs) allow us to plot the millisecond-by-millisecond time-course of visual word recognition processes (see Grainger and Holcomb, 2009) and provide a functional interpretation of deficient cognitive mechanisms based on existing knowledge of specific electrophysiological markers (Brandeis and Lehmann, 1986, 1994). We chose to use this technique to study the locus of the phonological deficit in dyslexia within a reading context. If reduced sensitivity to phonological information is the source of reading difficulties in 
dyslexia (as predicted by degraded phonological representations) then, from the moment that ERPs discriminate visual word stimuli such as pseudowords on the basis of their phonological properties, any differences between dyslexic and control readers should be manifest.

We know from ERP studies with normal, skilled readers that phonologically manipulated stimuli can reliably modulate the N2 peak, which occurs at least $100 \mathrm{~ms}$ before the N400 window. For instance, masked primes varied in phonological similarity to a target word elicit a graded amplification of N2 (N260: Grainger et al., 2006; Holcomb and Grainger, 2006). Furthermore, N2 amplitude has been shown to increase as a function of relative phonological and orthographic similarity of visually presented word rhyme pairs ${ }^{1}$ (Kramer and Donchin, 1987). A modulation of the N2 elicited by phonological mismatch is also observed when the expected final word of a sentence is replaced with a phonologically dissimilar, unexpected stimulus. This effect has been shown using both auditory (also known as the phonological mismatch/mapping negativity, PMN; Connolly and Phillips, 1994; D’Arcy et al., 2004; Diaz and Swaab, 2007; Newman and Connolly, 2009) and visual (Connolly et al., 1995; Savill et al., 2011) presentation. Furthermore, orthographic stimuli that are phonologically similar or even identical to an expected stimulus can show N2 attenuation similar to the expected stimulus congruent with their phonological acceptability (e.g., Vissers et al., 2006; Briesemeister et al., 2009; Savill and Thierry, 2011; Savill et al., 2011).

Looking at earlier influences of phonological information embedded in words, studies with normal readers have also reported phonological effects in reading within the P2 range. For instance, rhyming visual word pairs have been shown to increase P2 amplitudes relative to non-rhyming pairs (Barnea and Breznitz, 1998; Kong et al., 2010). Other studies have shown effects of phonetic consistency of Chinese characters radicals read silently as early as $170 \mathrm{~ms}$ post-stimulus onset (Lee et al., 2007; Hsu et al., 2009). Given that phonetic consistency relates to the frequency of the phonological mapping to a character, Hsu et al. (2009) hypothesized that the $\mathrm{P} 2$ is sensitive to variations in the mapping between orthography and phonology. A similar conclusion was reached by Bles et al. (2007) in an ERP study examining the passive effects of word cohort size reduction in which participants simply monitored for change in letter color. The authors found that reduction in cohort size, which was achieved by letter-by-letter presentation, correlated with reduction in $\mathrm{P} 2$ amplitude. They proposed that the $\mathrm{P} 2$ is modulated by the inhibition of competing stimuli based on phonological or orthographic information. Consistent with this view, recent studies comparing pseudohomophones or homophones with words or pseudowords have also found modulations of the P2 peak (Meng et al., 2008; Zhang et al., 2009; Kong et al., 2010) with onset of difference found as early as $150 \mathrm{~ms}$ after stimulus onset (Sauseng et al., 2004; Braun et al., 2009). Braun et al. (2009), for example, found that pseudohomophones elicited greater P150 amplitudes as compared to orthographically similar pseudowords during a

${ }^{1}$ In this study, the N2 peak was largest to non-rhyming orthographically dissimilar word pairs "shirt-witch"; smallest to rhyming and orthographically similar pairs "match-patch," and of intermediate amplitude to non-rhyming, orthographically similar "catch-watch," and rhyming, orthographically dissimilar pairs "blare-stair." lexical decision task. They proposed that P2 (or, as they call it, P150) modulations in amplitude index the conflict between the unfamiliar orthographic representation of pseudohomophones and their familiar phonological representation, such that P2 amplitude is increased with increased competition. Interestingly, such interaction between phonological and orthographic information is delayed when the primes are not consciously perceived, in which case ERP modulations are found later, e.g., in or beyond the N250 range (Grainger et al., 2006; Ashby and Martin, 2008). Therefore, if phonological representations are impaired in dyslexia, it is reasonable to expect group differences in the $\mathrm{P} 2-\mathrm{N} 2$ range in relation to phonology-orthography interactions during reading.

However, most of the previous electrophysiological studies with dyslexic participants have shown differential effects between groups for phonological manipulation in visually presented words fairly late in the processing stream, i.e., from within the so-called N400 range. The N400 wave is a large negative deflection typically elicited in linguistic tasks involving violations of semantic expectation in sentence (e.g., Kutas and Hillyard, 1980, 1984; van Berkum et al., 1999; Hagoort et al., 2004) and single word priming contexts (Bentin et al., 1985, 1993), but is also elicited by other forms of expectancy violation in language, such as mismatching stimuli in rhyming tasks (Rugg, 1984; Rugg and Barrett, 1987). Studies reporting N400 differences between dyslexic and control readers with respect to phonological processing of visual word stimuli are confined to studies of rhyme judgment, in which dyslexic individuals typically show an attenuated N400 (Ackerman et al., 1994; McPherson et al., 1998; Rüsseler et al., 2007). Such observations have been taken as electrophysiological evidence of phonological processing difficulties in dyslexia (Rüsseler et al., 2007). N400 differences observed in rhyme judgment, however, can be influenced by anomalies in domain-general cognitive processes including working memory (e.g., Gunter et al., 2003), integration (Holcomb, 1993), inhibition (Gunter et al., 2003), and/or decision-making processes (Brown and Hagoort, 1993; Holcomb, 1993; Connolly and Phillips, 1994; Chwilla et al., 1995). This is particularly relevant, because rhyming judgment is a fairly complex, abstract task reliant on working memory for retrieval, maintenance, and segmentation of the phonologic representation of the first stimulus into onset and rime and comparison with the rime of the following target (Besner, 1987). This means that we ought to consider earlier modulations elicited by phonological and orthographic interactions in reading.

Recently, we investigated early phonological effects in dyslexic adults making homophony judgments on visual word stimuli (Savill and Thierry, 2011). By comparing responses to words primed by pseudowords orthogonally manipulated for orthographic and phonological similarity, we found that, like controls, dyslexic adults showed early phonological priming effects in the $\mathrm{N} 2$ and $\mathrm{P} 3$ ranges (attenuated N2 and increased P3). Main effects of phonological priming only showed differences between groups in the P600 range, a stage of stimulus re-evaluation. We did, however, find that the interactive effects of orthographic and phonological priming differed between groups for peaks spanning the P2, N2, and P3 ranges, following reduced orthographic priming effects in the $\mathrm{N} 1$ range in the dyslexic group. These results indicate that the processing of orthographic information and its later integration with 
phonological information is problematic in dyslexia, rather than sensitivity to phonological information per se; at least within the context of a demanding meta-linguistic homophony judgment task.

To determine whether processing differences between dyslexic and unimpaired readers are present from the onset of readingrelated phonological analysis or whether differences emerge after phonological access has taken place in a more natural reading context, we decided to record ERP modulations elicited by phonological and orthographic priming during sentence reading. This study expands on a task that has previously been shown to elicit phonological modulations of the N2 in normal readers (Savill et al., 2011). To adapt the task for use with dyslexic participants, we increased the size of the stimulus set from Savill et al. (2011) and created high-cloze probability sentences (e.g." "Clare went on a diet to lose __" ending either in (a) its expected best completion word ("weight"), (b) a word homophonic to the expected word ("wait"), (c) a pseudohomophone of the expected word ("wate"), or (d) an unexpected word ("string"). Since three of the four conditions were phonologically very close, and should have been primed by each sentence context phonologically, this enabled us to see how phonological representations were accessed from different, unexpected orthographic forms in dyslexic readers.

We were primarily interested to see whether dyslexic readers would show reduced early effects of phonological manipulations in the $\mathrm{N} 2$ range (i.e., less $\mathrm{N} 2$ attenuation, following phonologically reduced N2 amplitudes seen in Vissers et al., 2006; Grainger and Holcomb, 2009; Savill et al., 2011). We also anticipated that mismatching orthographic and phonological information (i.e., in the case of phonologically matched but orthographically incorrect homophones and pseudohomophones) would induce conflict during lexical access and increase P2 mean amplitude (Bles et al., 2007; Braun et al., 2009; Hsu et al., 2009) and we investigated whether such modulation would be different in dyslexic readers (we did not test this in Savill et al. (2011) due to the paper's focus on phonological main effects). Furthermore, since previous ERP studies of visual word processing in dyslexic participants have predominantly shown effects of phonological manipulations in the N400 range, we investigated whether group differences would also/alternatively appear at later, post-perceptual stages of processing.

In order to test automatic versus controlled phonological processing, we tested participants using two different tasks performed on the same stimuli: a semantic-judgment task we termed "orthosemantic" focusing on orthography following Savill et al. (2011) ("is the final word the best way to complete the sentence?"); and a task we named "phono-semantic," which demanded focus on phonological form ("does the final word of the sentence sound like the best way to complete the sentence?"). We predicted that ERPs would provide evidence for a phonological deficit in reading in one of two ways:

(i) If the phonological deficit affecting reading in dyslexia has its source in degraded phonological representations and/or deficiency in extracting phonological information from written stimuli, dyslexic participants should show reduced sensitivity to phonological information and thus should display reduced phonological priming in response to homophones and pseudohomophones in both tasks. Therefore, we expected reduced
N2 amplitude decreases for these conditions relative to the unrelated condition in dyslexic participants as compared to matched controls.

(ii) Alternatively, if we can find no evidence of group differences in early stimulus evaluation stages, but differences manifest later in processing (e.g., beyond $300 \mathrm{~ms}$ post-stimulus onset), this would indicate that the deficit in dyslexia is not apparent during decoding and/or perception phases, but related to more integrative, attention-regulated, stages of phonological analysis which involve working memory and re-evaluation mechanisms.

Finally, the use of two tasks enabled us to test the potential role of overt attention to phonology during reading. Indeed, if the processes at work are under the voluntary control of the participants, attending to orthography ("ortho-semantic" task), and phonology ("phono-semantic" task) should yield different patterns across tasks and, what is more, interact with participant group.

\section{MATERIALS AND METHODS PARTICIPANTS}

Twelve adult participants with developmental dyslexia (six females, mean age 20.8 years) and 12 control adults (six females, mean age 22.9 years) participated in this study approved by the local Ethics committee of Bangor University. Participants were all students at Bangor University and had given informed consent to participate. All were right-handed according to the Edinburgh handedness inventory and native English speakers with normal or corrected-to-normal vision. Our dyslexic participants had a confirmed diagnosis of developmental dyslexia from an educational psychologist and were recruited through the university's Dyslexia Unit or through advertisement via the university's participant panel and were paid for participation. The dyslexic group consisted of high-functioning individuals who had compensated for their difficulties such that their reading level was within a normal range but at a level inconsistent with their academic ability. Performance on a series of subtests taken from the Dyslexia Adult Screening Test (DAST; Nicolson and Fawcett, 1998), Wide Range Achievement Test (WRAT-3; Jastak and Wilkinson, 1993), Wechsler Individual Achievement Test (WIAT-II; Wechsler, 2005), and Wechsler Adult Intelligence Scale (WAIS-III; Wechsler, 1997) showed that the dyslexic group performed significantly poorer than the control group across reading and spelling measures (Table 1).

\section{STIMULI}

To allow for the possibility of a greater loss of experimental trials from performance error due to testing dyslexic participants, we created additional stimuli to expand the stimulus set used by Savill et al. (2011). High-cloze sentences for which the best completion had an existing semantically unrelated homophone were created (e.g., "Clare went on a diet to lose___ _: best completion is "weight"; homophone is "wait"). These were supplemented with filler high-cloze sentences for which the final word had a unique phonological form. All sentences were normed by 26 native English speakers who completed them with the most expected word. Sentences selected for the study had at least $92 \%$ terminal word agreement. Pseudohomophones of the target word were created to form the pseudohomophone con- 
Table 1 | Group performance on psychometric subtests.

\begin{tabular}{|c|c|c|c|c|c|}
\hline & \multicolumn{2}{|c|}{ Control group ( $n=12$ ) } & \multicolumn{2}{|c|}{ Dyslexic group ( $n=12$ ) } & \multirow[t]{2}{*}{$\boldsymbol{t}$} \\
\hline & M & SD & M & SD & \\
\hline Age (years) & 22.92 & 6.13 & 20.75 & 1.29 & 1.20 \\
\hline One minute reading (DAST) & 117.25 & 11.99 & 96.17 & 15.68 & $3.70^{* *}$ \\
\hline Pseudoword reading (WIAT⿳亠口冋) & 114.67 & 5.55 & 90.17 & 14.62 & $5.43^{* * *}$ \\
\hline Rapid naming (DAST; s) & 25.08 & 3.75 & 31.58 & 10.19 & $-2.07^{*}$ \\
\hline Digit span (WAISa) & 11.75 & 2.34 & 9.08 & 2.35 & $2.78^{*}$ \\
\hline
\end{tabular}

Raw scores are reported unless otherwise stated.

a Standardized scores.

${ }^{*} p<0.05$. ${ }^{* *} p<0.01$. ${ }^{* *} p<0.001$.

dition (e.g., "wate") and a word semantically unrelated to the sentence stem was chosen for the unrelated condition (e.g., "string"). The final stimulus set consisted of 48 test sentences, shown once with their best completion, a homophone of the best completion, a pseudohomophone of the best completion, and an unrelated stimulus. A further two sets of 96 filler sentences were created: (a) a set of sentences ending with best completion words to be used in one of the tasks ("ortho-semantics") and (b) a set of sentences ending with unrelated homophones or pseudohomophones to be used in the other task ("phono-semantics"). The purpose of the fillers was to ensure equally probable yes or no responses in both tasks: In the ortho-semantic task a yes response was expected for best completions (48 items) and fillers (96 items) with homophones (48), pseudohomophones (48) and unrelated (48) requiring a no response; and for the phono-semantic task a yes response was expected for best completions (48), homophones (48), and pseudohomophones (48), with a no for unrelated (48), and filler items (96). Word lengths varied between 3 and 10 letters (terminal word $M=4.9, \mathrm{SD}=1.3$ ) and terminal words did not significantly differ in length across conditions $(p>0.2)$. Kucera-Francis written frequency and concreteness of the sentence final words were controlled between best completion, homophone and unrelated conditions $(p>0.1)$. All pseudohomophones used were piloted in the 26 participants mentioned above to verify pronunciation was homophonic to the target word. Finally, the orthographic properties of the pseudohomophone stimuli did not differ from the other conditions in terms of constrained bigram and trigram counts and averaged orthographic neighbor frequency (verified by http://www.neuro.mcw.edu/mcword/, Medler and Binder, 2005) and were similar in orthographic overlap with best completion words as the homophones were (according to their normalized edit distance, see Lambert et al., 1999). A list of the stimuli used is given in the Appendix.

\section{PROCEDURE}

Participants were seated comfortably in a dimly lit, sound-attenuated room in front of a projector screen. They were instructed to fixate the center of the screen and perform one of two tasks: (a) in the "ortho-semantic" task, they were asked to press a designated key for final words which were expected according to the sentence context and another for any other ending; (b) in the "phono-semantic" task, they were asked to press a key for final words that sounded like the expected completion of sentences and another key for phonologically inadequate endings. Sentences were presented using EPrime (Psychology Software Tools, Inc., Pittsburgh, USA) at the center of the screen, at eye-level, one word at a time, subtending a maximum angle of $3.7^{\circ}$, in black Times New Roman font on a white background. Experimental trials were presented in pseudo-random order across five blocks such that filler and test trials were evenly distributed. Each test trial consisted of a fixation cross displayed for $200 \mathrm{~ms}$, individual words in lower case displayed for $200 \mathrm{~ms}$ and separated by $300 \mathrm{~ms}$ inter-stimulus intervals featuring a fixation cross (Figure 1). After presentation of each final word the screen remained blank for a fixed period of $2000 \mathrm{~ms}$ to allow for participant response. A further $1000 \mathrm{~ms}$ separated trials. Task order and response sides were counterbalanced between participants.

The EEG data was recorded from $37 \mathrm{Ag} / \mathrm{AgCl}$ electrodes, placed in an elastic cap according to the extended 10-20 system, using Nuamps amplifiers (NeuroScan ${ }^{\mathrm{TM}}$, Sterling, USA). The online reference was the left mastoid and $\mathrm{FPz}$ served as the ground electrode. Electrodes positioned above and below the left eye recorded vertical eye movement. Electrode impedance was maintained below $5 \mathrm{k} \Omega$. Recordings were band-pass filtered off-line between 0.1 and $30 \mathrm{~Hz}$ using a zero-phase shift digital filter. Eye blinks were mathematically corrected using the correction provided by Edit 4.3 (NeuroScan $^{\mathrm{TM}}$, Sterling, USA). The continuous EEG was sliced into epochs ranging from -100 to $1000 \mathrm{~ms}$ after the onset of the target word. Epochs with voltage exceeding $\pm 75 \mu \mathrm{V}$ were automatically rejected. After baseline correction in reference to pre-stimulus activity, individual averages were re-referenced to the average of the mastoids. Individual averages were computed from correct trials in experimental condition (more than 35 epochs from each task for each case) and averaged together to produce grand-mean averages. Behavioral data were collected simultaneously to ERP data.

\section{DATA ANALYSIS}

Time windows for mean amplitude analyses were defined for the control group on the basis of mean global field power, expectations from previous experiments using similar stimuli (e.g., Connolly et al., 1995; Vissers et al., 2006; Thierry et al., 2008; Savill et al., 2011) and visual inspection of topographic distribution of ERP 


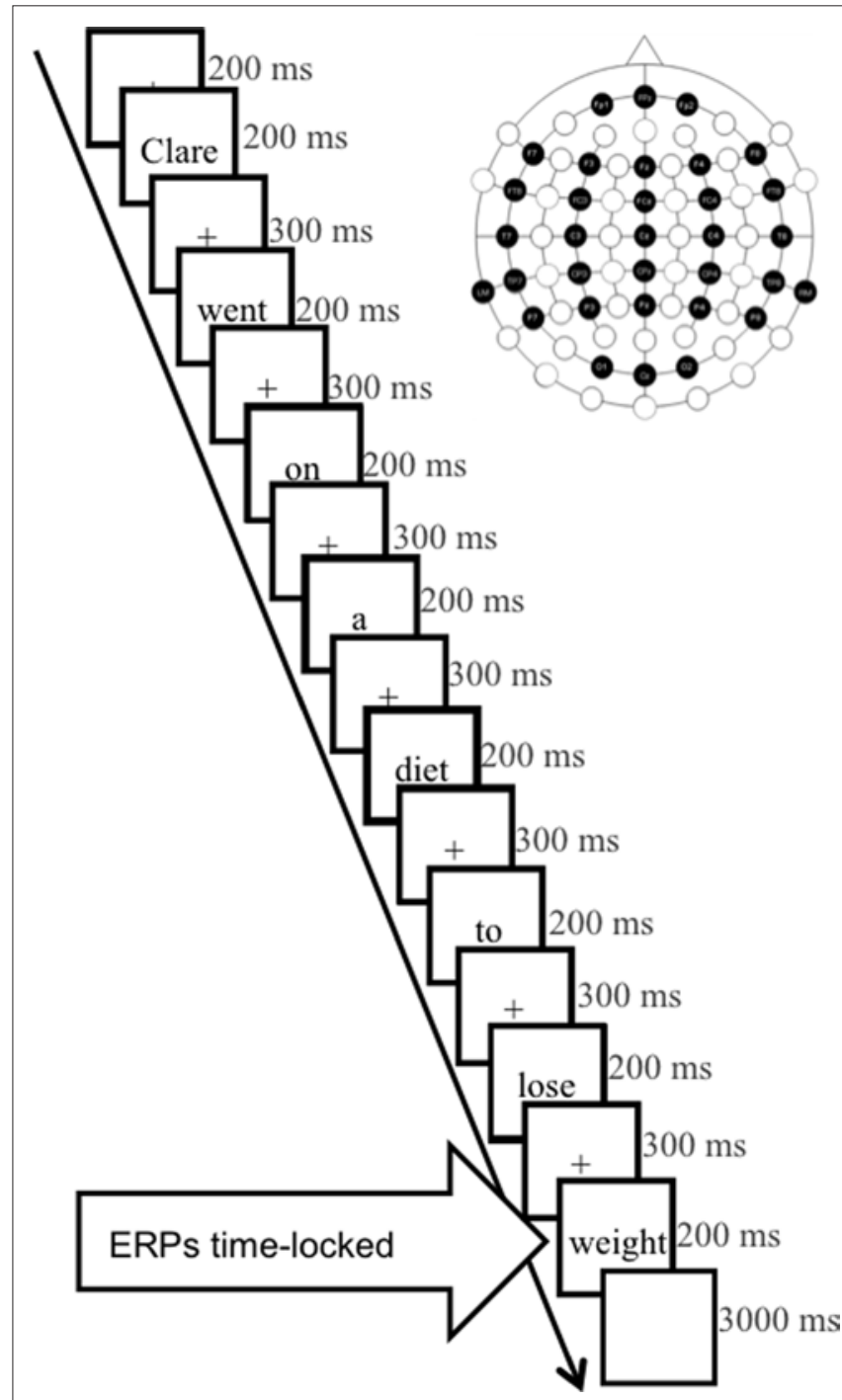

FIGURE 1 | Schematic of a single trial.

modulations (Luck, 2005). The expected P1/N1/P2/N2 peaks were observed, followed by a visible $\mathrm{P} 3$ a peak in the control group only. Windows of analysis for the control group were $80-110 \mathrm{~ms}$ for the P1; 140-170 ms for the N1; 160-210 for the P2; 250-350 ms for the N2, 350-450 ms for the P3a; and 470-670 ms for the P600.

To determine appropriate time windows for mean amplitude analyses in the dyslexic group, automatic peak detection was performed on large temporal windows encompassing each peak to check for significant group differences in overall peak latency (70-110 ms for the P1; 130-180 ms for the N1; 160-230 ms for the P2; 250-370 ms for the N2, 340-470 ms for the P3a; and $470-700 \mathrm{~ms}$ or the P600). Peak detection was time-locked to the electrode of maximal amplitude for each observed peak: $\mathrm{O} 2$ for the P1; P7 for the N1; and FCz for the P2, N2, and P3a. As both the $\mathrm{P} 2$ peak and the P600 peak were found to peak significantly later in the dyslexic group, with a delay of approximately 16 and $26 \mathrm{~ms}$ respectively, the analysis windows were adjusted to $180-230 \mathrm{~ms}$ for P2 mean amplitudes and to 500-700 ms for P600 mean amplitudes in the dyslexic group. No other peaks showed a significant delay and so for all other peaks the same analysis window was used as for the control group.

Mean amplitudes were measured at electrodes selected $a$ priori based on classical topography of main components and checked for maximal sensitivity based on visual inspection: $\mathrm{O} 1, \mathrm{O} 2, \mathrm{P} 7$, and $\mathrm{P} 8$ electrodes for the $\mathrm{P} 1 ; \mathrm{O} 1, \mathrm{O} 2, \mathrm{P} 7$, and $\mathrm{P} 8$ for the $\mathrm{N} 1 ; \mathrm{FC} 3$, FC4, FCz, and $\mathrm{Cz}$ for the P2, N2, and P3a peaks and Cz, CP3, CP4, $\mathrm{CPz}$ for the $\mathrm{P} 600$.

Mean ERP amplitudes and peak latencies were subjected to a mixed ANOVA with task ("ortho-semantic," "phono-semantic"), sentence condition (best completion, homophone, pseudohomophone, unrelated), and electrode as within-subject factors, and participant group (control, dyslexic) as between-subject factor. Error rates and reaction times (RTs) were also analyzed by means of a mixed ANOVA with task and condition as within-subject factors and participant group as between-subject factor. GreenhouseGeisser corrections of degrees of freedom were applied where appropriate.

\section{RESULTS \\ BEHAVIORAL DATA}

Statistical analyses revealed a main effect of group on both accuracy, $F_{1,22}=4.40, p=0.05$, and RTs, $F_{1,22}=13.79, p<0.01$, such that dyslexic participants were overall less accurate and slower than matched controls (Figure 2). Sentence condition significantly influenced performance accuracy, $F_{3,66}=17.34, p<0.001$ and correct RT, $F_{3,66}=14.07, p<0.001$. Accuracy was significantly lower for homophone endings than any other condition. RTs, meanwhile, were significantly faster for pseudohomophone endings, and unrelated endings elicited significantly slower reaction times than best completions. There was also a near-significant group by condition interaction with respect to accuracy $(p=0.08)$, relating to poorer accuracy in the homophone condition in the dyslexic group compared to the other conditions. Task also interacted significantly with condition in terms of accuracy $\left(F_{3,66}=6.09, p<0.01\right)$. Post hoc analyses showed that this interaction was driven by significantly poorer accuracy in the homophone condition in the "ortho-semantic" task, compared with no differences between conditions in the "phonosemantic" task. Task interacted significantly with condition also in terms of RT $\left(F_{3,66}=5.35, p<0.01\right)$. Post hoc tests showed that pseudohomophones elicited significantly faster RTs compared to all other conditions in the "ortho-semantic" task, whereas in the "phono-semantic" task only the unrelated words elicited slower RTs than the other conditions. A trend for a task by group interaction on accuracy $(p=0.08)$ was driven by a trend in the dyslexic group to perform less accurately in the "ortho-semantic" task compared to the "phono-semantic" task $(p=0.09)$, whilst the control group showed no significant difference between tasks $(p=0.69)$.

\section{EVENT-RELATED POTENTIAL RESULTS}

No significant task effects were observed on ERP peak latencies or mean amplitudes, therefore valid EEG epochs for each trial of both tasks were averaged together to increase statistical power (accepted epochs $M=83.20, \mathrm{SD}=11.42$; no significant differences between condition or group). All results reported below relate to the combined task averages. 
No significant differences in P1 mean amplitude or latency were found between groups or conditions. The N1 tended to be smaller in the dyslexic group, as indicated by a group effect on N1 mean amplitudes $\left(F_{1,22}=4.34, p<0.05\right.$; see Figure 3). No significant experimental modulations of the N1 were observed.

The P2 was significantly modulated by sentence condition $\left(F_{3,66}=5.54, p<0.01\right)$. Post hoc tests showed that this effect was driven by the homophone and pseudohomophone conditions eliciting significantly larger responses compared to the unrelated condition (both $p<0.01$ ). No significant group differences on mean amplitude were found (all $p>0.50$ ). P2 peak latency was also significantly affected by sentence condition $\left(F_{3,66}=5.50, p<0.01\right)$, such that the unrelated condition elicited shorter latencies relative to the other conditions (all $p<0.05$ ). Analyses also showed a main effect of group $\left(F_{1,22}=7.01, p<0.05\right)$ indicating significantly longer $\mathrm{P} 2$ latencies overall in the dyslexic group (control $M=183 \mathrm{~ms}$; dyslexic $M=199 \mathrm{~ms}$ ).

Sentence condition significantly modulated mean N2 amplitude $\left(F_{3,66}=36.55, p<0.001\right.$; Figure 4$)$ such that unrelated words elicited greater negativity in this range compared to all other sentence

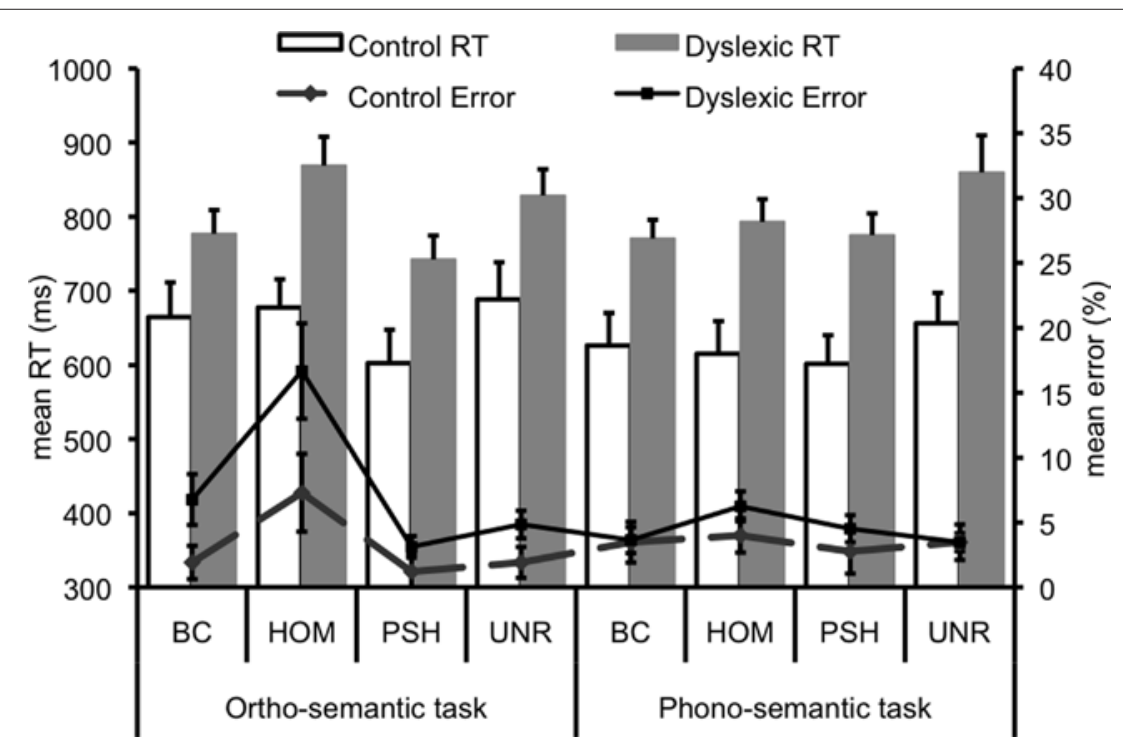

FIGURE 2 | Behavioral data for both tasks. Error bars represent 1 SE. BC, best completion; HOM, homophone; PSH, pseudohomophone; Unr, unrelated.

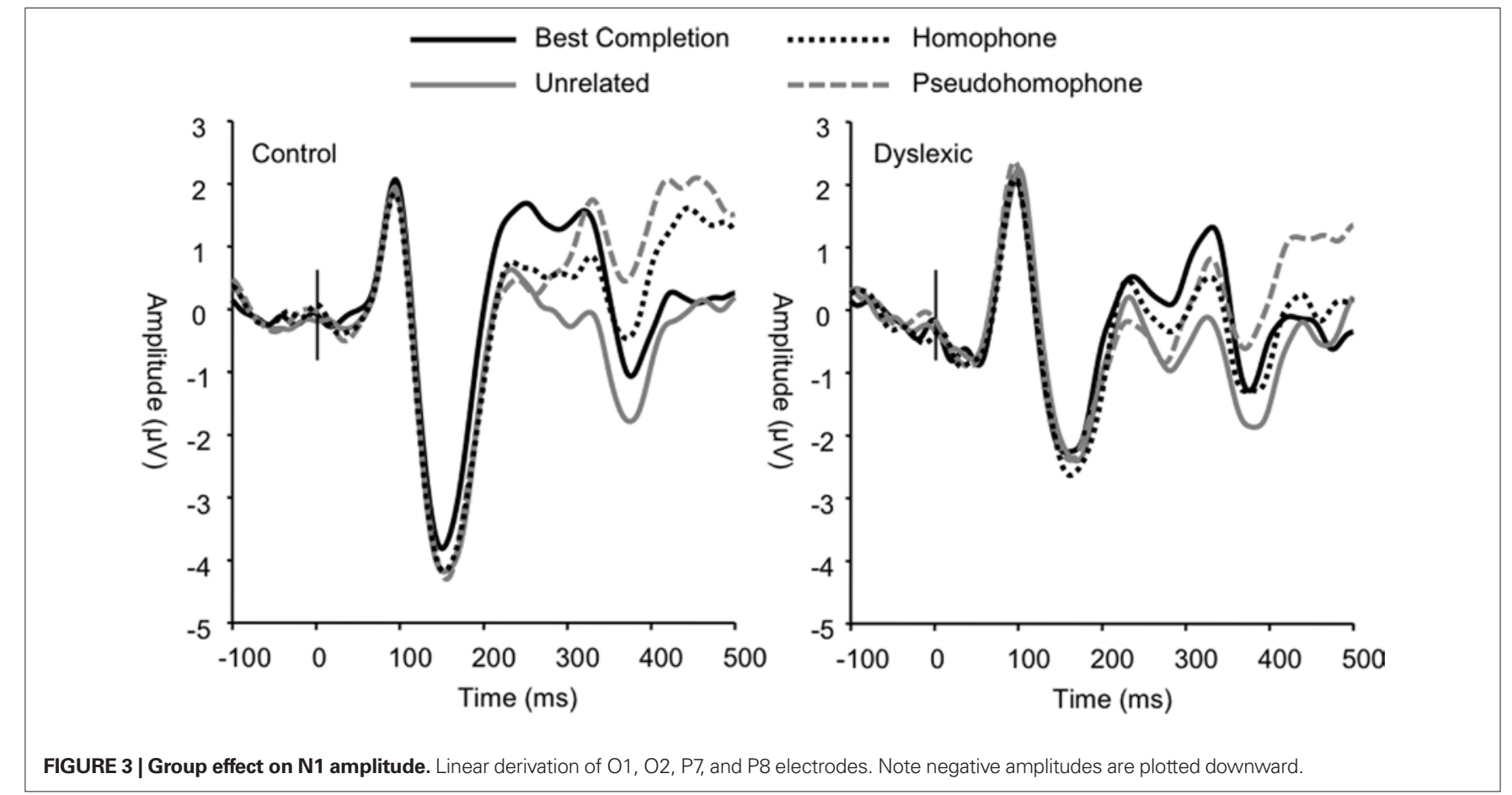


conditions (all $p<0.001$ ). N2 latencies were also significantly modulated by sentence condition $\left(F_{3,66}=3.21, p<0.05\right)$ due to the unrelated condition eliciting significantly shorter latencies than the homophone and pseudohomophone conditions $(p<0.05)$. No group differences were found in the $\mathrm{N} 2$ range (condition $\times$ group amplitude, $p=0.77$; latency, $p=0.30$ ).

The frontocentral P3 was significantly modulated by sentence condition $\left(F_{3,66}=12.72, p<0.001\right)$. This effect related to significantly larger P3a amplitudes elicited in the homophone and pseudohomophone conditions relative to the best completion and unrelated conditions ( $\operatorname{each} p<0.01$ ). The condition effect was qualified by a main effect of group on P3a amplitude, confirming that the P3a was significantly larger in the control group $\left(F_{1,22}=15.11\right.$, $p<0.001$; Figure 5) and by a significant interaction of group and condition $\left(F_{3,66}=3.19, p<0.05\right)$. Subsequent group-wise analyses showed that the control group showed a strong condition effect in the same direction as the observed overall condition effect $\left(F_{3}\right.$, ${ }_{33}=11.32, p<0.001$ ), showing significant differentiation of pseudohomophone and homophone conditions from best completion and unrelated conditions (all $p<0.01$ ), while the dyslexic group showed an effect driven only by smaller amplitudes to the unrelated condition compared to each other condition $\left(F_{3,33}=4.51, p<0.05\right)$.

A trend for $\mathrm{P} 3$ a peak latency differences induced by experimental condition was also found $(p=0.06)$, such that the best completion condition elicited significantly shorter latencies compared to the unrelated condition.

The P600 wave was also significantly modulated by sentence condition $\left(F_{3,66}=8.03, p<0.001\right.$; see Figure 6) irrespective of group. Pairwise comparisons showed that this effect was due to significantly attenuated amplitudes for the best completion condition relative to each of the other conditions, respectively (all $p<0.01$ ). Pairwise comparisons did not show significant differences in $\mathrm{P} 600$ amplitude between homophone, pseudohomophone, and unrelated conditions (all $p>0.20$ ). P600 peak latency was also significantly affected by sentence condition $\left(F_{3,66}=11.36, p<0.001\right)$, such that the homophone and pseudohomophone conditions elicited shorter latencies relative to the best completion and unrelated conditions (all $p<0.01$ ). Analyses also showed a main effect of group on P600 latency $\left(F_{1,22}=4.56, p<0.05\right)$ indicating significantly longer P600 latencies overall in the dyslexic group (control $M=540 \mathrm{~ms}$; dyslexic $M=576 \mathrm{~ms}$ ).

Bivariate correlations performed on mean amplitudes of ERP peaks for each experimental condition with their respective behavioral data are given in Table 2.

Table 2 | Significant correlations between individual mean amplitudes and behavioral data for each condition.

\begin{tabular}{|c|c|c|c|c|}
\hline & N1 & P2 & N2 & P3a \\
\hline \multicolumn{5}{|l|}{ BC accuracy } \\
\hline HOM accuracy & $-0.406^{*}$ & & & \\
\hline \multicolumn{5}{|l|}{ PSH accuracy } \\
\hline \multicolumn{5}{|l|}{ UNR accuracy } \\
\hline BC RT & & & & $-0.656^{* *}$ \\
\hline HOM RT & & & $-0.414^{*}$ & $-0.595^{* *}$ \\
\hline PSH RT & & & $-0.427^{*}$ & $-0.743^{* *}$ \\
\hline UNR RT & & & & $-0.532 * *$ \\
\hline
\end{tabular}

Values are Pearson $r$ coefficients $(n=24) .{ }^{*} p<0.05 ;{ }^{* *} p<0.01$ (two-tailed).

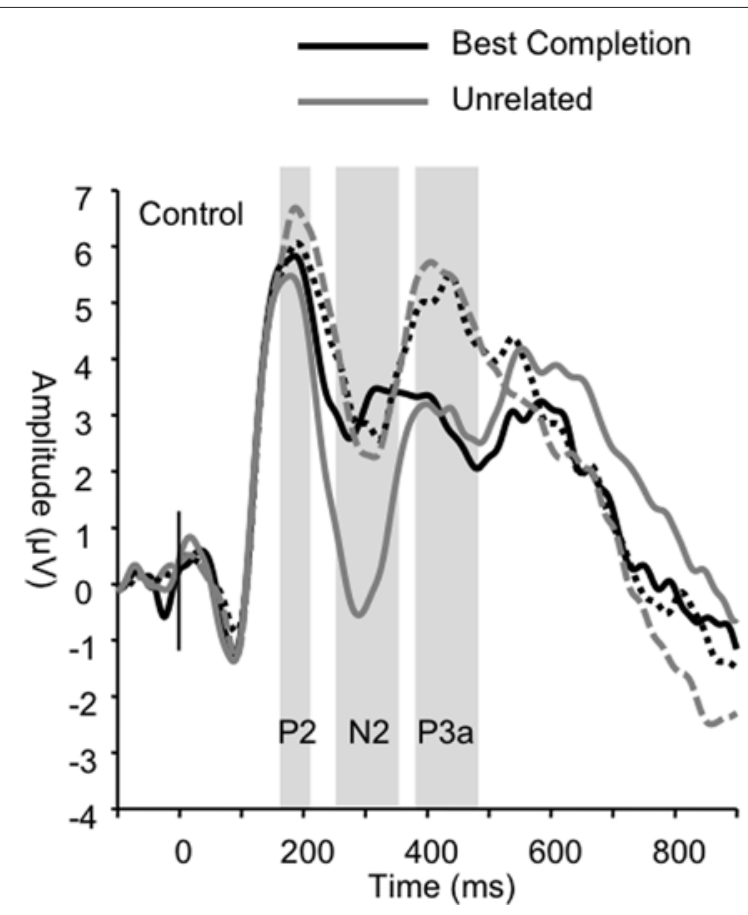

\section{.......... Homophone \\ --n-- Pseudohomophone}

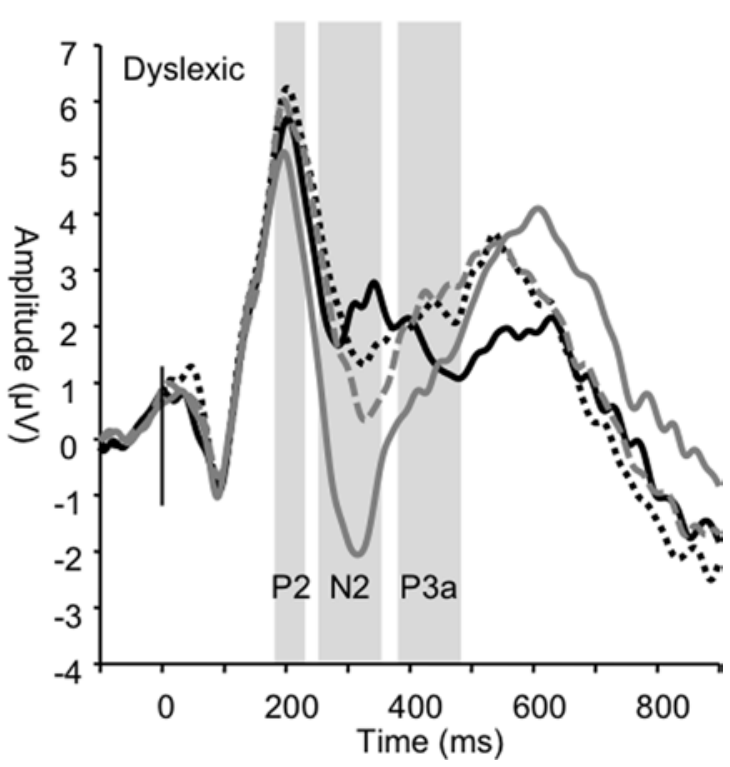

FIGURE 4 | Group grand averages showing P2, N2, and P3a peaks based on a linear derivation of FC3, FC4, FCz, and Cz electrodes. Time windows for mean amplitude analyses are marked by the gray bars. 

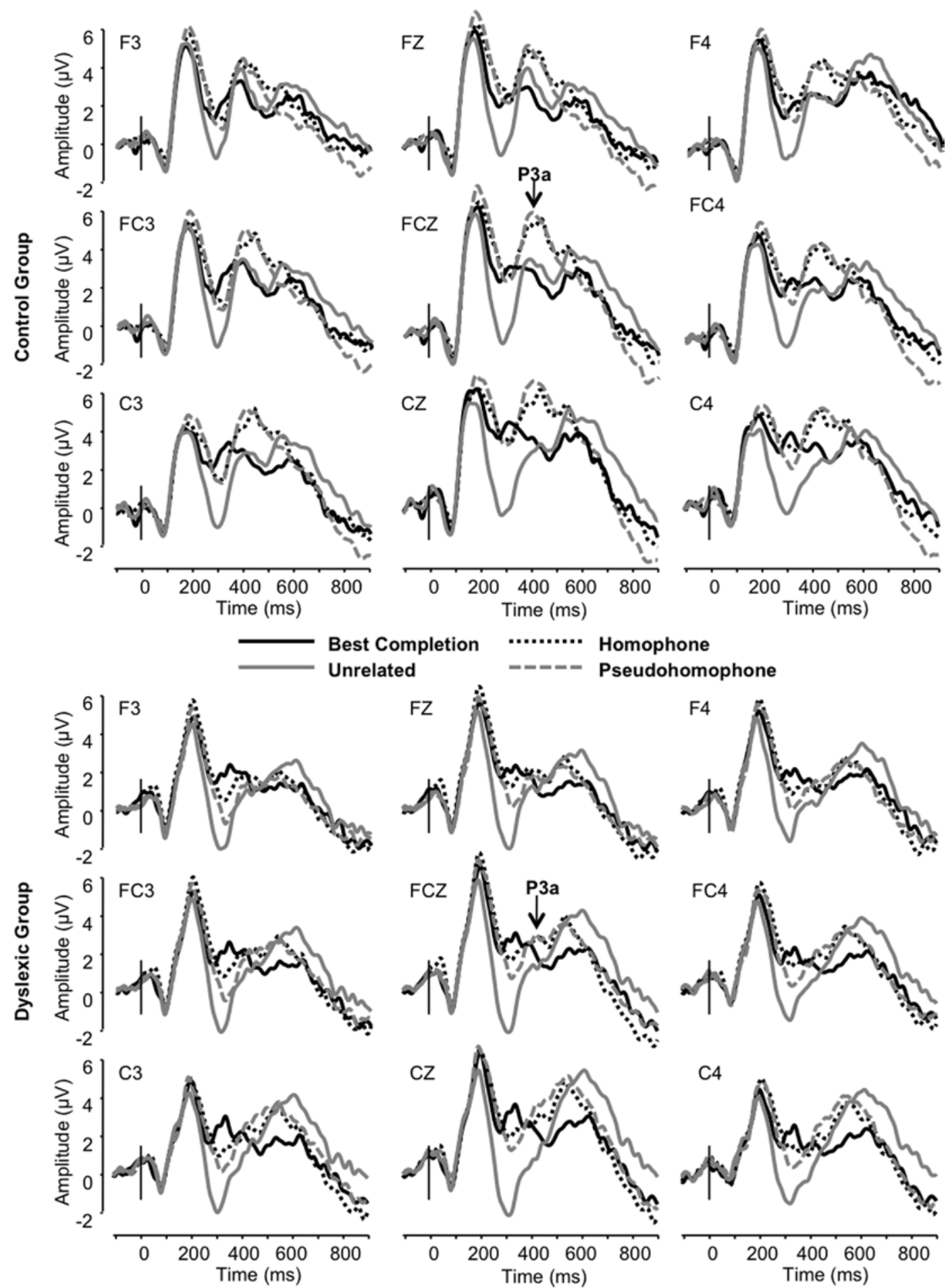

FIGURE 5 | Grand averages of frontocentral electrodes showing the diffuse group difference in P3a modulation.

\section{DISCUSSION}

This study aimed at detecting differences between individuals with developmental dyslexia and matched controls in orthographic/phonological integration mechanisms using ERPs.
We found early significant ERP modulations by orthographic and phonological priming in both the participant groups. However, despite poorer behavioral performance in the dyslexic group for the "ortho-semantic" and the "phono-semantic" variants of the task, 

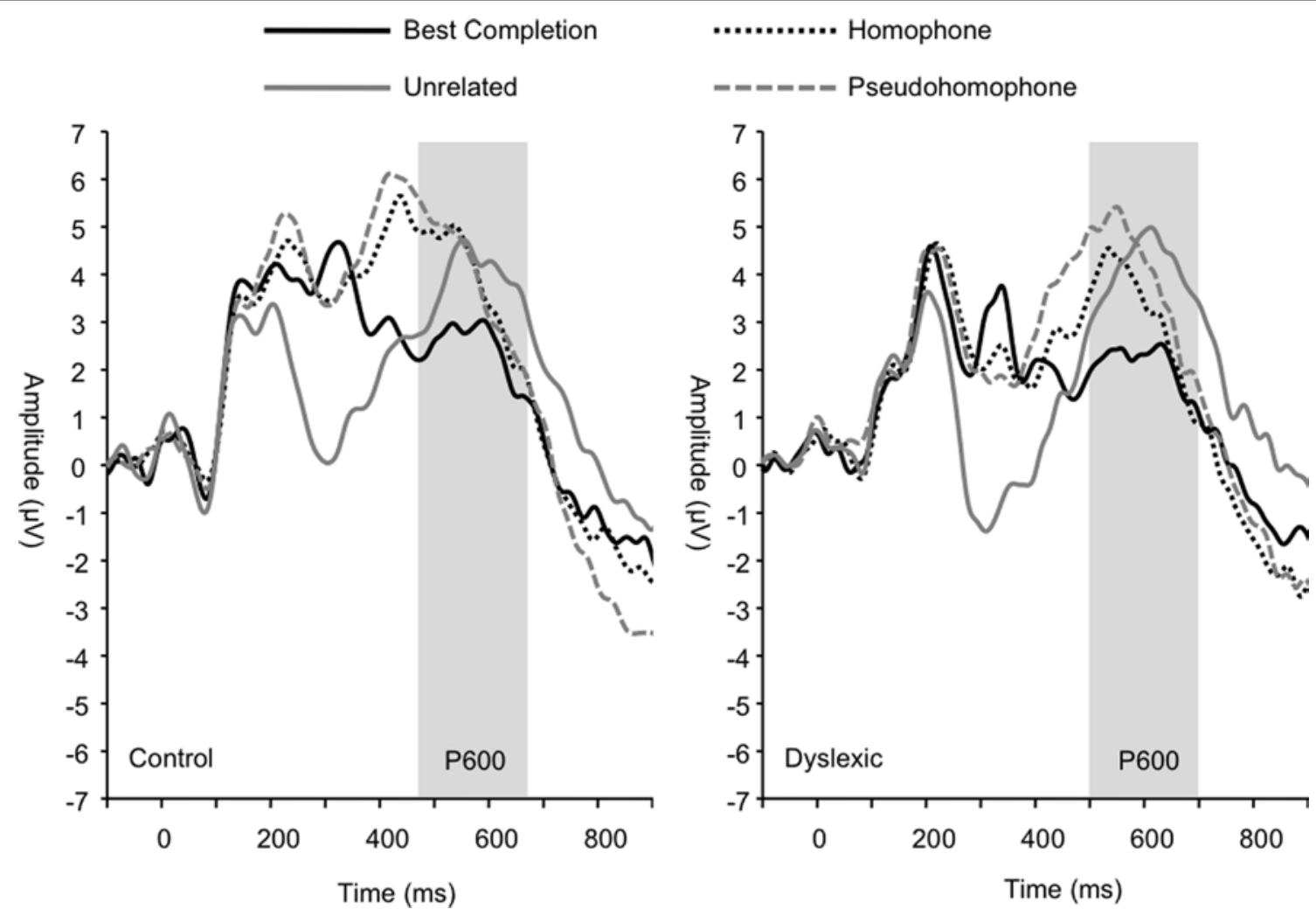

FIGURE 6 | Group grand averages showing the P600 peak, marked by the gray bar. Linear derivation of $\mathrm{CP} 3, \mathrm{CP} 4, \mathrm{CPz}$, and Pz electrodes.

ERP analyses failed to show any significant group differences in experimental effects before the $\mathrm{P} 3$ range and no task-specific effects were found. N1 amplitude was generally smaller in the dyslexic group but no experimental effects within or between groups were observed. P2 and N2 amplitude were both significantly affected by the experimental manipulation but these effects did not interact with group. By contrast, the $\mathrm{P} 2$ peak was significantly delayed in the dyslexic group as compared to the control group, but again there was no group by condition interaction. Moreover, in the $\mathrm{P} 3$ range, pseudohomophone and homophone stimuli elicited a significant, albeit late, frontocentral $\mathrm{P} 3 \mathrm{a}$ in control participants but failed to elicit a similar peak in this time window in the dyslexic group. The subsequent P600 wave peaked later in the dyslexic group but P600 amplitudes, which were increased to orthographically incorrect sentence completions, did not significantly differ between groups.

In this discussion we address the main result of our study, i.e., the differential P3a modulation in the two groups, first, and then we make observations regarding results in the N1, P2, N2, and P600 ranges.

\section{P3a: DEFICIENT ORTHOGRAPHICALLY/PHONOLOGICALLY DRIVEN ORIENTATION OF ATTENTION IN DYSLEXIA?}

We interpret the increase in P3a mean amplitude triggered by the homophone and pseudohomophone stimuli as a correlate of automatic attentional capture in the control group, because these stimuli had a "special" status: They were either the wrong completion which sounded like the correct completion in the "ortho-semantic" task or they were the correct completion but only in terms of phonology in the "phono-semantic" task. This special status prompted a P3a response that was not found for unambiguous targets or completely unrelated completions.

Critically, dyslexic participants failed to show this P3a modulation. The $\mathrm{P} 3 \mathrm{a}$ is traditionally conceived as a response evoked over frontocentral areas of the scalp by the engagement of working memory following shifts in the orientation of attention (Squires et al., 1975; Donchin and Coles, 1988; Knight, 1997; Polich, 2007). It is classically elicited by deviant non-target stimuli in the context of an oddball paradigm (Courchesne et al., 1975; Knight, 1984; Katayama and Polich, 1996a,b; Spencer et al., 1999, 2001; Daffner et al., 2000; Simons et al., 2001; Debener et al., 2005; Sawaki and Katayama, $2006,2007,2008)$ and has been shown to be modulated by the degree of difficulty involved in discriminating distracters from targets (Cormerchero and Polich, 1998; Polich and Comerchero, 2003; Hagen et al., 2006). The P3a indexes automatic engagement of focal attention during stimulus evaluation (e.g., Katayama and Polich, 1998) for further processing of a stimulus as a potentially important signal (e.g., Daffner et al., 2000) and is thought to reflect context updating (Kok, 2001). In other words, our results suggest that normal readers automatically oriented their attention to these special, phonologically acceptable but orthographically unexpected 
stimuli, whereas dyslexic participants did not. This could stem from a visual-phonological integration failure or a general failure in orienting of attention to phonologically relevant material, possibly leading to deficient engagement of working memory, rather than a deficit in the perceptual decoding of orthographic and/or phonological information.

Previous studies have indeed reported reduced or absent P3a in participants with developmental dyslexia, using phonologically manipulated speech and tone oddball stimuli (Rüsseler et al., 2002; Fosker and Thierry, 2004; Hämäläinen et al., 2008). Fosker and Thierry (2004), for instance, found that the P3a elicited by phonological oddballs during an auditory lexical decision task in adult control participants was not found in the dyslexic group. However, when phonological oddballs were brought into the focus of attention, dyslexic participants produced $\mathrm{P} 3 \mathrm{~b}$ modulations comparable with controls (Fosker and Thierry, 2005). Rüsseler et al. (2002) have shown similar attentional modulations of dyslexic oddball effects on the P3 with tone stimuli. Anomalous frontal P3a-like modulations have also been shown in dyslexic adults engaged in tasks requiring shifts in spatial attention (Wijers et al., 2005). Overall, such results have led to the idea of impaired shifts and/or capacity for automatic attentional capture by phonological information rather than impaired phonological processing abilities.

This interpretation links with the literature derived from tasks with rapidly presented stimuli that propose disordered automatic orienting of attention (e.g., Facoetti et al., 2008) and sluggish attentional shifting in dyslexia (Hari and Renvall, 2001). Slow capture of attention has previously been observed in non-linguistic cueddetection and T2 detection in attentional blink tasks using visual and auditory stimuli in dyslexic children and adults (Brannan and Williams, 1987; Hari et al., 1999; Facoetti et al., 2003a,b, 2006, 2008, 2010; Buchholz and Aimola Davies, 2007; Lallier et al., 2010). Sluggish shifting of attention has also been reported in dyslexic individuals using auditory or visual stream segregation tasks (Helenius et al., 1999b; Petkov et al., 2005; Lallier et al., 2009). With respect to reading, sluggish attentional capture has been found to significantly predict non-word reading performance (Cestnick and Coltheart, 1999; Facoetti et al., 2006, 2010). Facoetti et al. (2008) hypothesized that a deficit in automatic attention could impact decoding due to deficient engagement and disengagement with each letter/grapheme. Such a deficit, along with the absence of the $\mathrm{P} 3 \mathrm{a}$ in our dyslexic group, is unlikely to relate to a general deficit in automatic attention, as dyslexic participants have shown intact automatic orientation of attention in non-rapid tasks using nonverbal stimuli (Facoetti et al., 2008, 2010).

Although we did not test sluggish attentional shifting (since SOA was longer than $200 \mathrm{~ms}$, e.g., Lallier et al., 2009), the present results are congruous with such interpretations derived from studies of visuospatial attention in decoding and whole word reading. In general terms, our data, which indicate a reduced tendency to react to, rather than detect, a mismatch between orthography and primed lexical phonological representations in dyslexia, are consistent with a deficit in engagement of attention with phonological information when it is not supported by expected orthographic mappings. In relation to visual attention hypotheses regarding developmental dyslexia, this could be due to a deficit in attentional engagement and disengagement with each letter/grapheme (Facoetti et al.,
2008); and/or to under-specified orthographic representation in the lexicon of dyslexic individuals (Bosse et al., 2007; Prado et al., 2007; Lassus-Sangosse et al., 2008; Lallier et al., 2010). Alternatively, the absent $\mathrm{P} 3 \mathrm{a}$ response in the dyslexic group could reflect a wider impairment in attentional filtering that could reduce their filtering of incorrect orthographic and/or relevant phonological stimuli. Roach and Hogben $(2007,2008)$ propose that such impairment would stem from a relative failure in uncertainty reduction in dyslexic individuals.

Importantly, the deviation in processing seems to be related to attentional capture rather than perceptual encoding or phonological access per se, since the dyslexic group studied here activated and accessed phonological lexical forms similarly to the control group (P2-N2 complex) as shown by the amplified response to homophones and pseudohomophones in the $\mathrm{P} 2$ range (see below, $\mathrm{P} 2-\mathrm{N} 2$ discussion). Furthermore, the significant correlations with RTs indicate that the attentional processes engaged in visual word analysis indexed by the $\mathrm{P} 3 \mathrm{a}$ impact processing efficiency. How could this relate to reading difficulties more broadly? We suggest that a general weakness in engaging attention with orthographicphonological correspondences could affect sensitivity to spelling and spelling errors, which in turn would impede the acquisition of accurate and stable lexical representations. Furthermore, our results are compatible with recent hypotheses of deficient working memory in relation to phonological analysis rather than perceptual encoding (e.g., Banai and Ahissar, 2006; Ramus and Szenkovits, 2008; Menghini et al., 2011).

A review of the neuroimaging literature in relation to $\mathrm{P} 3 \mathrm{a}$ origins, orthographic-phonological mapping, and functional correlates of developmental dyslexia offers interesting insights into the neuroanatomical substrates likely to be involved in the process under study.

Firstly, patient and neuroimaging data have shown that temporoparietal cortex (TPJ) is fundamentally involved in P3 generation (both the P3a and P3b) with additional involvement from prefrontal areas in the case of the novelty P3a (Knight, 1984; Knight et al., 1989; Yamaguchi and Knight, 1991; Bledowski et al., 2004; Linden, 2005; Polich, 2007). The inferior parietal areas, in particular, have been implicated in attentional orienting based on stimulus relevance (Downar et al., 2001; Kiehl et al., 2001; Serences et al., 2005).

Secondly, left inferior parietal areas have been specifically implicated in the integration of orthographic and phonological information (Booth et al., 2002, 2004, 2007; Chen et al., 2002; Borowsky et al., 2006; Cao et al., 2006; Nakamura et al., 2006; Bitan et al., 2007; Graves et al., 2010; Newman and Joanisse, 2011) and more generally in sublexical decoding processes (e.g., Jobard et al., 2003; Levy et al., 2009; Graves et al., 2010), phonological judgments (Stoeckel et al., 2009; Hartwigsen et al., 2010), and verbal working memory involvement (see Ravizza et al., 2011). Note that inferior frontal areas have also been shown to be significantly activated during phonological tasks in which working memory load is high (e.g., Nixon et al., 2004; Strand et al., 2008; Thierry et al., 2003; Graves et al., 2010).

Thirdly, temporoparietal areas have consistently been shown to be underactivated in dyslexic readers (e.g., Hoeft et al., 2007; see Richlan et al., 2009 for a review) and inferior frontal areas frequently show abnormal activation (with greater activity associated with greater behavioral compensation; e.g., Hoeft et al., 2011 etc.). For 
instance, consistent with our interpretation, Cao et al. (2006, 2008) found reduced activations in left inferior parietal lobe of dyslexic children performing rhyme judgments on stimuli with conflicting orthographic and phonological information (e.g., pint-mint, jazz-has versus press-list, gate-hate), and reduced functional connectivity between left inferior parietal lobe and left inferior frontal and fusiform gyri.

This convergence of functional data regarding the TPJ and inferior frontal cortex in terms of (a) generation of the P3a, (b) phonological analysis in reading, and (c) loci of abnormal activation in dyslexia, provide empirical support for a functional link between attention, phonological processing in reading, and developmental dyslexia. Therefore, the P3a effects in the present study support the existence of a physiological relationship between attentional orienting mechanisms and phonological sublexical processing in reading; a relationship likely to be dysfunctional in developmental dyslexia.

\section{N1: REDUCED ORTHOGRAPHIC SENSITIVITY IN DYSLEXIA?}

Significant differences in visual word form processing between dyslexic and control readers in the P1-N1 range, thought to be letterstring specific, have previously been reported (Helenius et al., 1999a; Wimmer et al., 2002; Maurer et al., 2007; Taroyan and Nicolson, 2009; Savill and Thierry, 2011). In the present study, however, the only significant effect in the N1 range was an overall reduction in amplitude in the developmental dyslexic participants as compared to controls. This could be taken as a sign of reduced general sensitivity to orthographic stimuli (Maurer et al., 2005). However, the observation of smaller N1 overall may simply reflect greater latency variation in the dyslexic group yielding smaller average amplitudes (control N1 latency SD = 12.58; dyslexic latency SD = 15.04; see Picton et al., 2000). Alternatively, other random between-group differences unconnected to stimulus processing may have affected $\mathrm{N} 1$ amplitudes between groups. Overall, global N1 differences that are not qualified by an interaction with experimental conditions ought to be interpreted cautiously. Whilst reduced N1 amplitudes may index some form of reduced orthographic input in the dyslexic group that might contribute to the effects we observe downstream, such data alone can provide little supporting evidence of differential sensory integration mechanisms in developmental dyslexia and normal reading.

\section{INTACT PHONOLOGICAL REPRESENTATIONS (P2 AND N2) BUT SLOW PROCESSING (P2 AND P600) IN DYSLEXIA?}

Both participant groups showed similar amplification of the P2 in the homophone and pseudohomophone conditions relative to the unrelated condition, as well as similar attenuation of N2 mean amplitude in the homophone and pseudohomophone conditions relative to the unrelated condition, irrespective of task. This suggests that dyslexic readers' phonological representations of the anticipated word were well specified and that grapheme-phoneme conversion mechanisms allowed extraction and identification of the stimuli's phonological form not significantly different from that observed in control participants. This absence of differences between groups in the pattern of P2 and N2 mean amplitudes across experimental conditions suggests that a deficit in early sensitivity to phonological information may not be the main source of the persistent phonological deficit in reading, at least in the case of high-functioning dyslexic adults. Furthermore, a study similar to ours with Chinese dyslexic children using a sentence paradigm in which the second character of two-character Chinese words was replaced with homophonic or orthographically similar characters also failed to find group differences in P2 amplitude, but instead revealed P2 latency effects and later N400 modulations (Meng et al., 2007). The elicitation of earlier P2 latencies for homophonic replacements as compared to baseline in both groups suggests that early phonological extraction from orthography was intact in the dyslexic participants tested.

The P2 has been reported to be affected by stimulus salience in relation to task relevance (Potts and Tucker, 2001; Potts, 2004; Kieffaber and Herrick, 2005). In contrast to P3 modulations, it is not, however, thought to index orienting of attention (Potts, 2004). Thus, finding only group differences in the latency of the P2 suggests that the dyslexic group successfully identified the phonologically salient but semantically and orthographically incongruent homophones and pseudohomophones, albeit slower than controls. The significant P2 differentiation of the incorrect orthographic completions on the basis of phonological match (homophones and pseudohomophones versus unrelated conditions) discourages an alternative interpretation of the later P3a group difference being simply due to a general lack of orientation to orthographic form in the dyslexic group. Indeed, the later significant increases in P600 amplitude to incorrect orthographic completions relative to the best completion seen in both groups (in line with previous observations of P600 increases to misspellings in highly constrained sentences; Vissers et al., 2006) shows that the dyslexic group was sufficiently sensitive to orthographic form for incorrect forms to elicit stimulus re-evaluation. Furthermore, as homophones and pseudohomophones elicited the largest P2 amplitudes (rather than the best completion) in both groups, which is compatible with interpretations of frontal P2 amplitudes as sensitive to orthographicphonological mapping and to competition between phonological and orthographic information, the absence of a later amplitude increase to the same stimuli within the $\mathrm{P} 3 \mathrm{a}$ range in the dyslexic group suggests that the incorrect orthographic-phonological conflict was detected early but did not engage attention. In addition, $\mathrm{ERP}$ effects in the $\mathrm{N} 2$ range showed phonological integration in the dyslexic group (indexed by attenuated N2 amplitudes) comparable to both the normal readers in the present study and those tested in Savill et al. (2011). This also corroborates recent results in dyslexic readers (Savill and Thierry, 2011) and, on the basis of its occurrence immediately before the P3a window over the same electrodes, suggests that the emergence of dysfunctional phonological responses in reading coincides with the failure of attentional engagement.

The only group difference we observed prior to P3a amplitude effects was the finding that P2 latencies were longer overall for the dyslexic group. This P2 latency delay suggests that the initiation of phonological mapping may have been delayed, which, in turn, could account for the differences observed downstream in the P3a range. In the absence of a P3a peak in the dyslexic group, we cannot infer whether attentional engagement processes were progressively delayed, however the observation of P600 modulations involved in orthographic monitoring also peaked later in the dyslexic group suggesting that word recognition may be slowed down throughout the processing window. This finding is consistent with that of 
Breznitz and colleagues, who found evidence for slower speed of processing during various forced-choice visual and auditory tasks, indexed by delayed $\mathrm{P} 2$ and $\mathrm{P} 3$ latencies in dyslexic readers (Breznitz and Meyler, 2003; Breznitz and Misra, 2003). These authors put forward the hypothesis of a temporal asynchrony between visual and auditory perceptual systems in dyslexia, which would affect word recognition because it requires synchronization of orthographic and phonological codes. Their and our data converge regarding the implication of slower engagement with orthographic and phonological code integration, in a context of intact perceptual analysis. However, our study differs in that it uses homophonic visual word stimuli and the consequent observation of a relative lack of attentional specificity in the context of orthographically inappropriate, but phonologically acceptable, stimuli. This contributes to the accumulating evidence supporting the key role of attentional processing in dyslexia and underlines the usefulness of techniques such as ERPs in the characterization of orthographic and phonological processing and, critically, the assessment of their interactions during reading.

\section{CONCLUSION}

In this study, we attempted to establish a link between the phonological deficit in dyslexia and visual word recognition using a reading task in a sentence context. The absence of a P3a modulation in dyslexic participants suggests that a failure to attend either

\section{REFERENCES}

Ackerman, P., Dykman, R., and Oglesby, D. (1994). Visual event-related potentials of dyslexic children to rhyming and nonrhyming stimuli. J. Clin. Exp. Neuropsychol. 16, 138-154.

Ahissar, M., Lubin, Y., Putter-Katz, H., and Banai, K. (2006). Dyslexia and the failure to form a perceptual anchor. Nat. Neurosci. 9, 1558-1564.

Ans, B., Carbonnel, S., and Valdois, S. (1998). A connectionist multi-trace memory model of polysyllabic word reading. Psychol. Rev. 105, 678-723.

Ashby, J., and Martin, A. (2008). Prosodic phonological representations early in visual word recognition. J. Exp. Psychol. Hum. Percept. Perform. 34, 224-236.

Banai, K., and Ahissar, M. (2006). Auditory processing deficits in dyslexia: task or stimulus related? Cereb. Cortex 16, 1718-1728.

Barnea, A., and Breznitz, Z. (1998). Phonological and orthographic processing of Hebrew words: electrophysiological aspects. J. Genet. Psychol. 159, 492-504.

Bentin, S., Kutas, M., and Hillyard, S. A. (1993). Electrophysiological evidence for task effects on semantic priming in auditory word processing. Psychophysiology 30, 161-169.

Bentin, S., McCarthy, G., and Wood, C. C. (1985). Event-related potentials, lexical decision and semantic priming.
Electroencephalogr. Clin. Neurophysiol. 60, 343-355.

Besner, D. (1987). Phonology, lexical access in reading, and articulatory suppression: a critical review. Q. J. Exp. Psychol. 39A, 467-478.

Bitan, T., Burman, D. D., Chou, T. L., Dong, L., Cone, N. E., Cao, F., Bigio, J. D., and Booth, J. R. (2007). The interaction of orthographic and phonological information in children: an fMRI study. Hum. Brain Mapp. 28, 880-891.

Bledowski, C., Prvulovic, D., Hoechstetter, K., Scherg, M., Wibral, M., Goebel, R., and Linden, D. E. J. (2004). Localizing P300 generators in visual target and distractor processing: a combined event-related potential and functional magnetic resonance imaging study. J. Neurosci. 24, 9353-9360.

Bles, M., Alink, A., and Jansma, B. M. (2007). Neural aspects of cohort-size reduction during visual gating. Brain Res. 1150, 143-154.

Blomert, L., Mitterer, H., and Paffen, C. (2004). In search of the auditory, phonetic, and/or phonological problems in dyslexia: context effects in speech perception. J. Speech Lang. Hear. Res. 45, 1030-1047.

Booth, J. R., Burman, D. D., Meyer, J. R., Gitelman, D. R., Parrish, T. R., and Mesulam, M. M. (2002). Functional anatomy of intra- and cross-modal lexical tasks. Neuroimage 16, 7-22.

to the correspondence between orthography and phonology, or to phonological relevance more generally, may be critical in the emergence of dyslexic symptoms, which may be exacerbated by slower initiation of ortho-phonological integration. By contrast, the absence of group differences in experimental effects in earlier time-windows immediately before the P3a peak (P2-N2 range) both suggests that early phonological extraction from orthographic stimuli may be intact and that dysfunction in sublexical analyses relating to phonological integration might not emerge until stages of attentional capture. However, one must be cautious before discarding earlier sensory integration mechanism deficits on the basis of null interactions. Future studies will further explore deficient orienting to orthographic forms and sensitivity to phonological information in relation to reading and the specificity of deficient orienting mechanisms in developmental dyslexia.

\section{ACKNOWLEDGMENTS}

The authors wish to thank Lydia Devenney for assistance with data collection, Liz Du Pré for her help with recruitment of the dyslexic participants and Marie Lallier for her helpful comments on the paper. This work was supported by the ESRC studentship PTA-031-2006-00242 and the British Foundation for Women Graduates. Guillaume Thierry is supported by the Economic and Social Research Council (ES/E024556/1) and the European Research Council (ERC-SG-209704).

Booth, J. R., Burman, D. D., Meyer, J. R., Zhang, L., Gitelman, D. R., Parrish, T. R., and Mesulam, M. M. (2004). Development of brain mechanisms for processing orthographic and phonological representations. J. Cogn. Neurosci. 16, 1234-1249.

Booth, J. R., Cho, S., Burman, D. D., and Bitan, T. (2007). Neural correlates of mapping from phonology to orthography in children performing an auditory spelling task. Dev. Sci. 10, 441-451.

Borowsky, R., Cummine, J., Owen, W. J., Friesen, C. K., Shih, F., and Sarty, G. E. (2006). FMRI of ventral and dorsal processing streams in basic reading processes: insular sensitivity to phonology. Brain Topogr. 18, 233-239.

Bosse, M.-L., Tainturier, M.-J., and Valdois, S. (2007). Developmental dyslexia: the visual attention span deficit hypothesis. Cognition 104, 198-230.

Brandeis, D., and Lehmann, D. (1986). Event-related potentials of the brain and cognitive processes: approaches and applications. Neuropsychologia 24, 151-168.

Brandeis, D., and Lehmann, D. (1994). "ERP mapping: a tool for assessing language disorders," in Cognitive Electrophysiology, eds H. J. Heinze, T. F. Mante, and G. R. Mangun (Boston: Birkhauser), 242-250.

Brannan, J. R., and Williams, M. C. (1987). Allocation of visual attention in good and poor readers. Atten. Percept. Psychophys. 41, 23-28.

Braun, M., Hutzler, F., Ziegler, J., Dambacher, M., and Jacobs, A. (2009). Pseudohomophone effects provide evidence of early lexico-phonological processing in visual word recognition. Hum. Brain Mapp. 30, 1977-1989.

Breznitz, Z., and Meyler, A. (2003). Speed of lower-level auditory and visual processing as a basic factor in dyslexia: electrophysiological evidence. Brain Lang. 85, 166-184.

Breznitz,Z., and Misra, M. (2003). Speed of processing of the visual-orthographic and auditory-phonological systems in adult dyslexics: the contribution of "asynchrony" to word recognition deficits. Brain Lang. 85, 486-502.

Briesemeister, B. B., Hofmann, M. J., Tamm, S., Kuchinke, L, Braun, M., and Jacobs, A. M. (2009). The pseudohomophone effect: evidence for an orthography-phonology-conflict. Neurosci. Lett. 455, 124-128.

Brown, C. M., and Hagoort, P. (1993). The processing nature of the N400: evidence from masked priming. $J$. Cogn. Neurosci. 5, 34-44.

Buchholz, J., and Aimola Davies, A. M. (2007). Attentional blink deficits shown in dyslexia depend on task demands. Vision Res. 47, 1292-1302.

Cao, F., Bitan, T., and Booth, J. R. (2008). Effective brain connectivity in children with reading difficulties during 
phonological processing. Brain Lang. 107, 91-101.

Cao, F., Bitan, T., Chou, T. L., Burman, D. D., and Booth, J. R. (2006). Deficient orthographic and phonological representations in children with dyslexia revealed by brain activation patterns. J. Child Psychol. Psychiatry 47, 1041-1050.

Cestnick, L., and Coltheart, M. (1999). The relationship between language processing and visual-processing deficits in developmental dyslexia. Cognition 71, 231-255.

Chen, Y., Fu, S., Iversen, S. D., Smith, S. M., and Matthews, P. M. (2002). Testing for dual brain processing routes in reading: a direct contrast of Chinese character and Pinyin reading using fMRI. J. Cogn. Neurosci. 14, 1088-1098.

Chwilla, D. J., Brown, C. M., and Hagoort, P. (1995). The $\mathrm{N} 400$ as a function of the level of processing. Psychophysiology $32,274-285$.

Connolly, J., Phillips, N., and Forbes, K. (1995). The effects of phonological and semantic features of sentenceending words on visual event-related brain potentials. Electroencephalogr. Clin. Neurophysiol. 94, 276-287.

Connolly, J. F., and Phillips, N. A. (1994). Event-related potential components reflect phonological and semantic processing of the terminal word of spoken sentences. J. Cogn. Neurosci. 6, 256-266.

Cormerchero, M. D., and Polich, J. (1998). P3a, perceptual distinctiveness, and stimulus modality. Brain Res. Cogn. Brain Res. 7, 41-48.

Courchesne, E., Hillyard, S. A., and Galambos, R. (1975). Stimulus novelty, task relevance, and visual evokedpotential in man. Electroencephalogr. Clin. Neurophysiol. 39, 131-143.

Daffner, K., Mesulam, M., Seinto, L., Calvo, V., Faust, R., and Holcomb, P. (2000). An electrophysiological index of stimulus unfamiliarity. Psychophysiology 37, 737-747.

D’Arcy, R., Connolly, J., Service, E., Hawco, C., and Houlihan, M. (2004). Separating phonological and semantic processing in auditory sentence processing: a high-resolution eventrelated brain potential study. Hum. Brain Mapp. 22, 40-51.

Debener, S., Makeig, S., Delorme, A., and Engel, A. (2005). What is novel in the novelty oddball paradigm? Functional signficance of the novelty P3 eventrelated potential as revealed by independent component analysis. Brain Res. Cogn. Brain Res. 22, 309-321.

Diaz, M., and Swaab, T. (2007). Electrophysiological differentiation of phonological and semantic integra- tion in word and sentence contexts. Brain Res. 1146, 85-100.

Donchin, E., and Coles, M. G. H. (1988). Is the P300 component a manifestation of context updating? Behav. Brain Sci. $11,357-374$.

Downar, J., Crawley, A. P., Mikulis, D. J., and Davis, K. D. (2001). The effect of task relevance on the cortical response to changes in visual and auditory stimuli: an event-related fMRI study. Neuroimage 14, 1256-1267.

Facoetti, A., Lorusso, M., Paganoni, P., Cattaneo, C., Galli, R., and Mascetti, G. (2003a). The time course of attentional focusing in dyslexic and normally reading children. Brain Cogn. 53, 181-184.

Facoetti, A., Lorusso, M. L., Paganoni, P., Cattaneo, C., Galli, R., Umiltà, C., and Mascetti, G. G. (2003b). Auditory and visual automatic attention deficits in developmental dyslexia. Brain Res. Cogn. Brain Res. 16, 185-191.

Facoetti, A., Ruffino, M., Peru, A., Paganoni, P., and Chelazzi, L. (2008). Sluggish engagement and disengagement of non-spatial attention in dyslexic children. Cortex 44, 1221-1233.

Facoetti, A., Trussardi, A., Ruffino, M., Lorusso, M., Cattaneo, C., Galli, R., Molteni, M., and Zorzi, M. (2010). Multisensory spatial attention deficits are predictive of phonological decoding skills in developmental dyslexia. J. Cogn. Neurosci. 22, 1011-1025.

Facoetti, A., Zorzi, M., Cestnick, L., Lorusso, M. L., Molteni, M., Paganoni, P., Umilta, C., and Mascetti, G. G. (2006). The relationship between visuospatial attention and nonword reading in developmental dyslexia. Cogn. Neuropsychol. 23, 841-855.

Fosker, T., and Thierry, G. (2004). P300 investigation of phoneme change detection in dyslexic adults. Neurosci. Lett. 357, 171-174.

Fosker, T., and Thierry, G. (2005). Phonological oddballs in the focus of attention elicit a normal P3b in dyslexic adults. Brain Res. Cogn. Brain Res. 24, 467-475.

Fowler, A. E. (1991). "How early phonological development might set the stage for phoneme awareness," in Phonological Processes in Literacy: A Tribute to Isabelle Y. Liberman, eds. S. A. Brady and D. P. Shankweiler (Hillsdale, NJ: Lawrence Erlbaum), 97-117.

Geiger, G., Cattaneo, C., Galli, R., Pozzoli, U., Lorusso, M. L., Facoetti, A., and Molteni, M. (2008). Wide and diffuse perceptual modes characterized dyslexics in vision and audition. Perception 37, 1745-1764.

Grainger, J., and Holcomb, P. (2009). Watching the word go by: on the time-course of component processes in visual word recognition. Lang. Linguist. Compass 3, 128-156.

Grainger, J., Kiyonaga, K., and Holcomb, P. (2006). The time course of orthographic and phonological code activation. Psychol. Sci. 17, 1021-1026.

Graves, W. W., Desai, R., Humphries, C., Seidenberg, M. S., and Binder, J. R. (2010). Neural systems for reading aloud: a multiparametric approach. Cereb. Cortex 20, 1799-1815.

Gunter, T., Wagner, S., and Friederici, A. (2003). Working memory and lexical ambiguity resolution as revealed by ERPs: a difficult case for activation theories. J. Cogn. Neurosci. 15, 643-657.

Hagen, G. F., Gatherwright, J. R., Lopez, B. A., and Polich, J. (2006). P3a from visual stimuli: primary task difficulty effects. Int. J. Psychophysiol. 59, 8-14.

Hagoort, P., Hald, L., Bastiaansen, M., and Petersson, K. (2004). Integration of word meaning and world knowledge in language comprehension. Science 304, 438-441.

Hämäläinen, J., Leppänen, P., Guttorm, T., and Lyytinen, H. (2008). Eventrelated potentials to pitch and rise time change in children with reading disabilities and typically reading children. Clin. Neurophysiol. 119, 100-115.

Hari, R., and Renvall, H. (2001). Impaired processing of rapid stimulus sequences in dyslexia. Trends Cogn. Sci. 5, 525-532.

Hari, R., Valta, M., and Uutela, K. (1999). Prolonged attentional dwell time in dyslexic adults. Neurosci. Lett. 271, 202-204.

Hartwigsen, G., Baumgaertner, A., Price, C. J., Koehnke, M., Ulmer, S., and Siebner, H. R. (2010). Phonological decisions require both the left and right supramarginal gyri. Proc. Natl. Acad. Sci. U.S.A. 107, 16494-16499.

Helenius, P., Tarkiainen, A., Cornelissen, P., Hansen, P., and Salmelin, R. (1999a). Dissociation of normal feature analysis and deficient processing of letter-strings in dyslexic adults. Cereb. Cortex 9, 476-483.

Helenius, P., Uutela, K., and Hari, R. (1999b). Auditory stream segregation in dyslexic adults. Brain 122, 907-913.

Hoeft, F., McCandliss, B. D., Black, J. M., Gantman, A., Zakerani, N., Hulme, C., Lyytinen, H., Whitfield-Gabrieli, S., Glover, G. H., Reiss, A. L., and Gabrieli, J. D. E. (2011). Neural systems predicting long-term outcome in dyslexia. Proc. Natl. Acad. Sci.U.S.A. 108, 361-366.

Hoeft, F., Meyler, A., Hernandez, A., Juel, C., Taylor-Hill, H., Martindale, J. L., McMillon, G., Kolchugina, G., Black, J. M., Faizi, A., Deutsch, G. K., Siok, W. T., Reiss, A. L., Whitfield-Gabrieli,
S., and Gabrieli, J. D. E. (2007). Functional and morphometric brain dissociation between dyslexia and reading ability. Proc. Natl. Acad. Sci. U.S.A. 104, 4234-4239.

Holcomb, P., and Grainger, J. (2006). On the time course of visual word recognition: an event-related potential investigation using masked repetition priming. J. Cogn. Neurosci. 18, 1631-1643.

Holcomb, P. J. (1993). Semantic priming and stimulus degradation: implications for the role of the N400 in language processing. Psychophysiology 30, 47-61.

Hsu, C., Tsai, J., Lee, C., and Tzeng, O. (2009). Orthographic combinability and phonological consistency effects in reading Chinese phonograms: an event-related potential study. Brain Lang. 108, 56-66.

Jastak, S., and Wilkinson, G. (1993). The Wide Range Achievement Test-3. Wilmington, DE: Jastak Associates.

Jobard, G., Crivello, F., and TzourioMazoyer, N. (2003). Evaluation of the dual route theory of reading: a metaanalysis of 35 neuroimaging studies. Neuroimage 20, 693-712.

Katayama, J., and Polich, J. (1996a). P300 from one-, two-, and threestimulus auditory paradigms. Int. J. Psychophysiol. 23, 33-40.

Katayama, J., and Polich, J. (1996b). P300, probability, and the three-tone paradigm. Electroencephalogr. Clin. Neurophysiol. 100, 555-562.

Katayama, J., and Polich, J. (1998). Stimulus context determines $\mathrm{P} 3 \mathrm{a}$ and P3b. Psychophysiology 35, 23-33.

Kieffaber, P., and Herrick, W. (2005). Event-related potential correlates of task switching and switch costs. Psychophysiology 42, 56-71.

Kiehl, K. A., Laurens, K. R., Duty, T. L., Forster, B. B., and Liddle, P. F. (2001). An event-related fMRI study of visual and auditory oddball tasks. $J$. Psychophysiol. 15, 221-240.

Knight, R. T. (1984). Decreased response to novel stimuli after prefrontal lesions in man. Electroencephalogr. Clin. Neurophysiol. 59, 9-20.

Knight, R. T. (1997). Distributed cortical network for visual attention. J. Cogn. Neurosci. 9, 75-91.

Knight, R. T., Scabini, D., Woods, D., and Clayworth, C. (1989). Contributions of temporal-parietal junction to the human auditory P300. Brain Res. 502, 109-116.

Kok, A. (2001). On the utility of P3 amplitude as a measure of processing capacity. Psychophysiology 38, 557-577.

Kong, L., Zhang, J. X., Kang, C., Du, Y. C., Zhang, B., and Wang, S. (2010). P200 and phonological processing in 
Chinese word recognition. Neurosci. Lett. 473, 37-41.

Kramer,A., and Donchin,E. (1987). Brain potentials as indices of orthographic and phonological interaction during word matching. J. Exp. Psychol. Learn. Mem. Cogn. 13, 76-86.

Kutas, M., and Hillyard, S. (1980). Reading senseless sentences: brain potentials reflect semantic incongruity. Science 207, 203-220.

Kutas, M., and Hillyard, S.A. (1984). Brain potentials during reading reflect word expectancy and semantic association. Nature 307, 161-163.

Lallier, M., Donnadieu, S., Berger, C., and Valdois, S. (2010). A case study of developmental phonological dyslexia: is the attentional deficit in the perception of rapid stimuli sequences amodal? Cortex 46, 231-241.

Lallier, M., Thierry, G., Tainturier, M. J., Donnadieu, S., Peyrin, C., Billard, C., and Valdois, S. (2009). Auditory and visual stream segregation in children and adults: an assessment of the amodality assumption of the 'sluggish attentional shifting' theory of dyslexia. Brain Res. 1302, 132-147.

Lambert, B. L., Lin, S.-J., Chang, K.-Y., and Gandhi, S. K. (1999). Similarity as a risk factor in drug-name confusion errors: the look-alike (orthographic) and sound-alike (phonetic) model. Med. Care 37, 1214-1225.

Lassus-Sangosse, D., N'guyen-Morel, M. A., and Valdois, S. (2008). Sequential or simultaneous visual processing deficit in developmental dyslexia? Vision Res. 48, 979-988.

Lee, C. Y., Tsai, J. L., Chan, W. H., Hsu, C. H., Hung, D. L., and Tzeng, O. J. (2007). Temporal dynamics of the consistency effect in reading Chinese: an eventrelated potentials study. Neuroreport $18,147-151$.

Levy, J., Pernet, C., Treserras, S., Boulanouar, K., Aubry, F., Démonet, J. F., Celsis, P., and García, A. V. (2009). Testing for the dual-route cascade reading model in the brain: an fMRI effective connectivity account of an efficient reading style. PLoS ONE 4, e6675. doi: 10.1371/journal. pone. 0006675

Linden, D. E. J. (2005). The P300: where in the brain is it produced and what does it tell us? Neuroscientist 11,563-576.

Luck, S. J. (2005). An introduction to the event-related potential technique. Cambridge, MA: MIT Press.

Manis, F. R., Mcbride-Chang, C., Seidenberg, M. S., Keating, P., Doi, L. M., Munson, B., and Petersen, A. (1997). Are speech perception deficits associated with developmental dyslexia? J. Exp. Child Psychol. 66, 211-235.
Maurer, U., Brem, S., Bucher, K., and Brandeis, D. (2005). Emerging neurophysiological specialization for letter strings. J. Cogn. Neurosci. 17, 1532-1552.

Maurer, U., Brem, S., Bucher, K., Kranz, F., Benz, R., Steinhausen, H.-C., and Brandeis, D. (2007). Impaired tuning of a fast occipito-temporal response for print in dyslexic children learning to read. Brain 130, 3200-3210.

McPherson, W., Ackerman, P., Holcomb, P., and Dykman, R. (1998). Eventrelated brain potentials elicited during phonological processing differentiate subgroups of reading disabled adolescents. Brain Lang. 62, 163-185.

Medler, D. A., and Binder, J. R. (2005). MCWord: An On-Line Orthographic Database of the English Language. Available at: http://www.neuro.mcw. edu/moword/

Meng, X., Jian, J., Shu, H., Tian, X., and Zhou, X. (2008). ERP correlates of the development of orthographical and phonological processing during Chinese sentence reading. Brain Res. 1219, 91-102.

Meng, X., Tian, X., Jian, J., and Zhou, X. (2007). Orthographic and phonological processing in Chinese dyslexic children: an ERP study on sentence reading. Brain Res. 1179, 119-130.

Menghini, D., Finzi, A., Benassi, M., Bolzani, R., Facoetti, A., Giovagnoli, S., Ruffino, M., and Vicari, S. (2010). Different underlying neurocognitive deficits in developmental dyslexia: a comparative study. Neuropsychologia 48, 863-872.

Menghini, D., Finzi, A., Carlesimo, G. A., and Vicari, S. (2011). Working memory impairment in children with developmental dyslexia: is it just a phonological deficity? Dev. Neuropsychol. 36, 199-213.

Nakamura, K., Hara, N., Kouider, S., Takayama, Y., Hanajima, R., Sakai, K., and Ugawa, Y. (2006). Task-guided selection of the dual neural pathways for reading. Neuron 52, 557-564.

Newman, R., and Connolly, J. (2009). Electrophysiological markers of prelexical speech processing: evidence for bottom-up and top-down effects on spoken word processing. Biol. Psychol. $80,114-121$.

Newman, R. L., and Joanisse, M. F. (2011). Modulation of brain regions involved in word recognition by homophonous stimuli: an fMRI study. Brain Res. 1367, 250-264.

Nicolson, R. I., and Fawcett, A. J. (1998). The Dyslexia Adult Screening Test. London: Psychological Corporation.

Nixon, P., Lazarova, J., Hodinott-Hill, I., Gough, P., and Passingham, R. (2004). The inferior frontal gyrus and pho- nological processing: an investigation using rTMS. J. Cogn. Neurosci. 16, 289-300.

Pennington, B. F., and Bishop, D. V. M. (2009). Relations among speech, language, and reading disorders. Аnnu. Rev. Psychol. 60, 283-306.

Petkov, C. I., O'Connor, K. N., Benmoshe, G., Baynes, K., and Sutter, M. L. (2005). Auditory perceptual grouping and attention in dyslexia. Brain Res. $\operatorname{Cog} n$. Brain Res. 24, 343-354.

Picton, T. W., Bentin, S., Berg, P., Donchin, E., Hillyard, S. A., Johnson, R. Jr., Miller, G. A., Ritter, W., Ruchkin, D.S., Rugg, M. D., and Taylor, M. J. (2000). Guidelines for using human eventrelated potentials to study cognition: recording standards and publication criteria. Psychophysiology 37, 27-152.

Polich, J. (2007). Updating P300: an integrative theory of $\mathrm{P} 3 \mathrm{a}$ and $\mathrm{P} 3 \mathrm{~b}$. Clin. Neurophysiol. 118, 2128-2148.

Polich, J., and Comerchero, M. D. (2003). P3a from visual stimuli: typicality, task, and topography. Brain Topogr. $15,141-152$.

Potts, G. F. (2004). An ERP index of task relevance evaluation of visual stimuli. Brain Cogn. 56, 5-13.

Potts, G. F., and Tucker, D. M. (2001) Frontal evaluation and posterior representation in target detection. Brain Res. Cogn. Brain Res. 11, 147-156.

Prado, C., Dubois, M., and Valdois, S. (2007). The eye movements of dyslexic children during reading and visual search: impact of the visual attention span. Vision Res. 47, 2521-2530.

Ramus, F. (2002). Outstanding questions about phonological processing in dyslexia. Dyslexia 7, 197-216.

Ramus, F., and Szenkovits, G. (2008). What phonological deficit? Q. J. Exp. Psychol. 61, 129-141.

Ravizza, S. M., Hazeltine, E., Ruiz, S., and Zhu, D. C. (2011). Left TPJ activity in verbal working memory: implications for storage- and sensory-specific models of short term memory. Neuroimage 55, 1836-1846.

Richlan, F., Kronbichler, M., and Wimmer, H. (2009). Functional abnormalities in the dyslexic brain: a quantitative meta-analysis of neuroimaging studies. Hum. Brain Mapp. 30, 3299-3308.

Roach, N. W., and Hogben, J. H. (2007). Impaired filtering of behaviourally irrelevant visual information in dyslexia. Brain 130, 771-785.

Roach, N. W., and Hogben, J. H. (2008). Spatial cueing deficits in dyslexia reflect generalised difficulties with attentional selection. Vision Res. 48, 193-207.

Ruffino, M., Trussardi, A. N., Gori, S., Finzi, A., Giovagnoli, S., Menghini, D., Benassi, M., Molteni, M., Bolzani,
R., Vicari, S., and Facoetti, A. (2010). Attentional engagement deficits in dyslexic children. Neuropsychologia 48, 3793-3801.

Rugg, M. (1984). Event-related potentials in phonological matching tasks. Brain Lang. 23, 225-240.

Rugg, M. D., and Barrett, S. E. (1987). Event-related potentials and the interaction between orthographic and phonological information in a rhyme-judgment task. Brain Lang. 32, 336-361.

Rüsseler, J., Becker, P., Johannes, S., and Münte, T. (2007). Semantic, syntactic, and phonological processing of written words in adult developmental dyslexic readers: an event-related brain potential study. BMC Neurosci. 8, 52. doi: 10.1186/1471-2202-8-52

Rüsseler, J., Kowalczuk, J., Johannes, S., Wieringa, B., and Münte, T. (2002). Cognitive brain potentials to novel acoustic stimuli in adult dyslexic readers. Dyslexia 8, 125-142.

Sauseng, P., Bergmann, J., and Wimmer, H. (2004). When does the brain register deviances from standard word spellings? - an ERP study. Brain Res. Cogn. Brain Res. 20, 529-532.

Savill, N., Lindell, A., Booth, A., West, G., and Thierry, G. (2011). Literate humans sound out words during silent reading. Neuroreport 11, 116-120.

Savill, N. J., and Thierry, G. (2011). Reading for sound with dyslexia: evidence for early orthographic and late phonological integration deficits. Brain Res. 1385, 192-205.

Sawaki, R., and Katayama, J. (2006). Stimulus context determines whether non-target stimuli are processed as task-relevant or distractor information. Clin. Neurophysiol. 117, 2532-2539.

Sawaki, R., and Katayama, J. (2007). Difficulty of discrimination modulates attentional capture for deviant information. Psychophysiology 44, 374-382.

Sawaki, R., and Katayama, J. (2008). Distractor $\mathrm{P} 3$ is associated with attentional capture by stimulus deviance. Clin. Neurophysiol. 119, 1300-1309.

Serences, J. T., Shomstein, S., Leber, A. B., Golay, X., Egeth, H. E., and Yantis, S. (2005). Coordination of voluntary and stimulus-driven attentional control in human cortex. Psychol. Sci. 16, 114-122.

Simons, R. F., Graham, F. K., Miles, M. A., and Chen, X. (2001). On the relationship of P3a and the novelty-P3. Biol. Psychol. 56, 207-218.

Snowling, M. J. (2000). Dyslexia, 2nd Edn. Oxford: Blackwell.

Spencer, K. M., Dien, J., and Donchin, E. (1999). A componential analysis of the 
ERP elicited by novel events using a dense electrode array. Psychophysiology 36, 409-414.

Spencer, K. M., Dien, J., and Donchin, E. (2001). Spatiotemporal analysis of the late ERP responses to deviant stimuli. Psychophysiology 38, 343-358.

Squires, N., Squires, K., and Hillyard, S. (1975). Two varieties of long-latency positive waves evoked by unpredictable auditory stimuli in man. Electroencephalogr. Clin. Neurophysiol. 38, 387-401.

Stoeckel, C., Gough, P. M., Watkins, K. E., and Devlin, J. T. (2009). Supramarginal gyrus involvement in visual word recognition. Cortex 45 , 1091-1096.

Strand, F., Forssberg, H., Klingberg, T., and Norrelgen, F. (2008). Phonological working memory with auditory presentation of pseudo-words - an event related fMRI Study. Brain Res. 1212, 48-54.

Swan, D., and Goswami, U. (1997). Phonological awareness deficits in developmental dyslexia and the phonological representations hypothesis. J. Exp. Child Psychol. 66, 18-41.

Taroyan, N.A., and Nicolson, R. I. (2009). Reading words and pseudowords in dyslexia: ERP and behavioural tests in English-speaking adolescents. Int. J. Psychophysiol. 74, 199-208.

Thierry, G., Ibarrola, D., Demonet, J. F., and Cardebat, D. (2003). Demand on verbal working memory delays haemodynamic response in the inferior prefrontal cortex. Hum. Brain Mapp. 19, 37-46.

Thierry, G., Martin, C. D., Gonzalez-Diaz, V., Rezaie, R., Roberts, N., and Davis, P. M. (2008). Event-related potential characterisation of the Shakespearean functional shift in narrative sentence structure. Neuroimage 40, 923-931.

Valdois, S., Bosse, M.-L., and Tainturier, M.-J. (2004). The cognitive deficits responsible for developmental dyslexia: review of evidence for a selective visual attentional disorder. Dyslexia 10, 339-363.

van Berkum, J., Hagoort, P., and Brown, C. (1999). Semantic integration in sentences and discourse: evidence from the N400. J. Cogn. Neurosci. 11, 657-671.

Vellutino, F. R., Fletcher, J. M., Snowling, M. J., and Scanlon, D. M. (2004). Specific reading disability (dyslexia): what have we learned in the past four decades? J. Child Psychol. Psychiatry 45, 2-40.

Vidyasagar, T. R., and Pammer, K. (2010). Dyslexia: a deficit in visuo-spatial attention, not in phonological processing. Trends Cogn. Sci. 14, 56-63.

Vissers, C. T. W. M., Chwilla, D. J., and Kolk, H. H. J. (2006). Monitoring in language perception: the effect of misspellings of words in highly constrained sentences. Brain Res. 1106, 150-163.

Wechsler, D. (1997). Weschsler Adult Intelligence Scale-III. San Antonio, TX: The Psychological Corporation.

Wechsler, D. (2005). Wechsler Individual Achievement Test, 2nd Edn. London: Harcourt.

Wijers, A., Been, P., and Romkes, K (2005). Dyslexics show a deviant lateralization of attentional control: a brain potential study. Neurosci. Lett. 374, 87-91.

Wimmer, H., Hutzler, F, and Wiener, C. (2002). Children with dyslexia and right parietal lobe dysfunction: eventrelated potentials in response to words and pseudowords. Neurosci. Lett. 331, 211-213.

Yamaguchi, S., and Knight, R. T. (1991) P300 generation by novel somatosensory stimuli. Electroencephalogr. Clin. Neurophysiol. 78, 50-55.

Zhang, Q., Zhang, J., and Kong, L. (2009). An ERP study on the time course of phonological and semantic activation in Chinese word recognition. Int. J. Psychophysiol. 73, 235-245.

Conflict of Interest Statement: The authors declare that the research was conducted in the absence of any commercial or financial relationships that could be construed as a potential conflict of interest.

Received: 18 January 2011; accepted: 09 June 2011; published online: 22 June 2011.

Citation: Savill NJ and Thierry G (2011) Electrophysiological evidence for impaired attentional engagement with phonologically acceptable misspellings in developmental dyslexia. Front. Psychology 2:139. doi: 10.3389/fpsyg.2011.00139

This article was submitted to Frontiers in Language Sciences, a specialty of Frontiers in Psychology.

Copyright (c) 2011 Savill and Thierry. This is an open-access article subject to a nonexclusive license between the authors and Frontiers Media SA, which permits use, distribution and reproduction in other forums, provided the original authors and source are credited and other Frontiers conditions are complied with. 


\section{APPENDIX}

\section{List of sentence stimuli.}

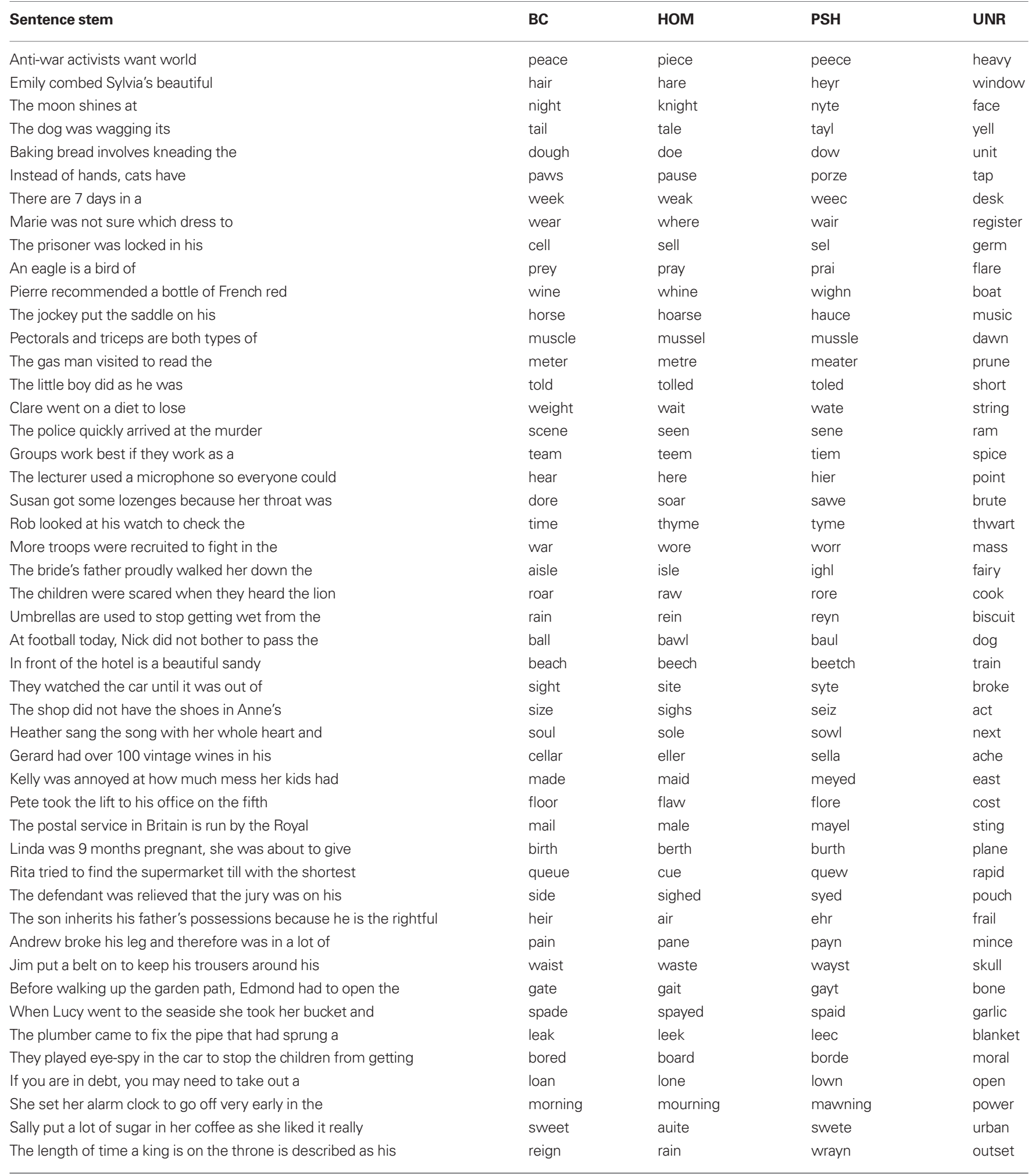

